\title{
PERBANDINGAN RENCANA ANGGARAN BIAYA ANTARA METODE SNI 2010 DAN ANALISIS HARGA SATUAN PEKERJAAN
}

\author{
Tahan \\ Program Studi Teknik Sipil, Fakultas Teknik, \\ Universitas Kristen Palangka Raya \\ Email: utuntahan10@gmail.com
}

\begin{abstract}
ABSTRAK
Rencana Anggaran Biaya adalah perkiraan biaya material, biaya upah, dan biaya lain-lain yang dibutuhkan untuk mendirikan suatu bangunan, dan sebagai pedoman analisis agar proses pembangunan tersebut berjalan secara efektif dan efisien. Rencana Anggaran Biaya memerlukan indeks bahan dan upah, yang didapatkan dari analisis harga satuan pekerjaan yang dikeluarkan resmi oleh BSN, seperti SNI 2008 dan 2010 serta Peraturan Menteri Pekerjaan Umum dan Perumahan Rakyat Nomor 28 Tahun 2016 tentang Pedoman Analisis Harga Satuan Pekerjaan Bidang Pekerjaan Umum, sebagai acuan dalam perhitungan pembangunan pemerintah, pengadaan barang dan jasa pemerintah. Untuk mengetahui seberapa besar dan metode yang lebih ekonomis dari Rencana Anggaran Biaya antara metode SNI 2010 dan metode Analisis Harga Satuan Pekerjaan Bidang Cipta Karya Peraturan Menteri Pekerjan Umum dan Perumahan Rakyat Nomor 28 Tahun 2016. Rencana Anggaran Biaya merupakan hasil perkalian antara volume suatu item pekerjaan dengan harga satuannya atau dirumuskan dengan: $\mathrm{RAB}=\Sigma[($ VOLUME) $\mathrm{x}$ HARGA SATUAN PEKERJAAN]. Harga Satuan Pekerjaan ialah, jumlah harga bahan dan upah tenaga kerja berdasarkan perhitungan analisis. Untuk mendapatkan harga satuan pekerjaan, maka harga satuan bahan, harga satuan upah, dan harga satuan alat harus diketahui terlebih dahulu yang kemudian dikalikan dengan indeks/ koefisien analisis yang telah ditentukan. Dari hasil perhitungan Rencana Anggaran Biaya, metode SNI 2010 memerlukan biaya Rp.19.131.776.000.00; sedangkan untuk metode Analisis Harga Satuan Pekerjaan Bidang Cipta Karya Peraturan Menteri Pekerjan Umum dan Perumahan Rakyat Nomor 28 Tahun 2016 memerlukan biaya Rp.19.634.780.000.00; Rencana Anggaran Biaya dari kedua metode tersebut mempunyai selisih anggaran biaya sebesar Rp.503.004.000.00; dengan persentase perbandingan sebesar 2,56 \%. Untuk penyusunan Rencana Anggaran Biaya diharapkan agar lebih teliti dalam membuat tahapan-tahapan pekerjaan yang akan dilaksanakan dan masih dibutuhkan metode SNI, dengan pertimbangan efisiensi dan efektivitas kerja, serta nilai lebih ekonomis.
\end{abstract}

Kata Kunci: Rencana Anggaran Biaya, SNI (Standar Nasional Indonesia), Analisis Harga 'Satuan Pekerjaan (AHSP).

\begin{abstract}
The cost budget plan is the estimated cost of materials, wages, and other costs of building a building, and as an analysis guide to effective and efficient operation of the building process. The price of a budget requires an index of materials and wages, obtained from an official BSN price analysis, such as the 2008 and 2010 state minister of public works and housing law no. 28 of 2016 on the government's task force price analysis guidelines, asa model for government development, the administration's supply of government goods and services. To find out how much and a more cost-effective method of spending will be between the 2010 sni method and the inventive field of work force analyse works by the general labor and people's housing ordinance no. 28 of 2016. The cost budget plan is a by-product of multiplying the volume of a job item with a unit price or defined by: $r a b=\operatorname{cost}$ [(volume) of a task force]. The price of a task force is, the price of materials and labor based on analytical calculations. To get the price of a task force, the price of a unit of materials, the price of a wage unit, and the price of an instrument unit must first be known which then multiplied by an analysis/coefficient index. According to the estimate of the cost of the budget plan, the 2010 sni method would cost $\$ 19,131,76,000$. As for the method of analyzing the
\end{abstract}


price of the labor force, the work of the general labor ministry and the housing of the people no. 28 of 2016 will cost $\$ 19,634,780,000$; The cost - budget plan of these two approaches had a costbudget margin of rp 503,004,000, 00; With a ratio of 2.56 percent. For creating a cost-budget plan is expected to be more thorough in making the stages of the work to be done and still require sni methods, with considerations of efficiency and effectiveness, and more economical value.

Keyword: cost-budget plan, SNI (Indonesia's national standard), price analysis'. Task force (ahsp).

\section{PENDAHULUAN}

Rencana Anggaran Biaya adalah perkiraan biaya material, biaya upah, dan biaya lain-lain yang dibutuhkan untuk mendirikan suatu bangunan, Rencana Anggara Biaya diperlukan sebagai pedoman analisis suatu pembangunan agar proses pembangunan tersebut berjalan secara efektif dan efisien, dalam perhitungan Rencana Anggaran Biaya tentu memerlukan indeks bahan dan upah. Indeks bahan dan upah didapatkan dari analisis harga satuan pekerjaan yang dikeluarkan resmi oleh Badan Standarisasi Nasional (BSN), seperti Standar Nasional Indonesia (SNI 2008 dan 2010).

Pada masa sekarang ini ini Kementerian Pekerjaan Umum dan Perumahan Rakyat melalui Badan Penelitian dan pengembangan melakukan sosialisasi sejumlah pedoman dalam Standar Nasional Indonesia (SNI) dan juga yang sedang gencar disosialisasikan adalah Peraturan Menteri Pekerjaan Umum dan Perumahan Rakyat (PUPR) Nomor 28 Tahun 2016 tentang Pedoman Analisis Harga Satuan Pekerjaan (AHSP) Bidang Pekerjaan Umum yang dimasukkan sebagai acuan dalam perhitungan pembangunan pemerintah, pengadaan barang dan jasa pemerintah.

Sehubungan dengan adanya Peraturan Menteri Pekerjaan Umum dan Perumahan Rakyat (PUPR) Nomor 28 Tahun 2016 tentang Pedoman Analisis Harga Satuan Pekerjaan (AHSP) Bidang Pekerjaan Umum yang dimasukkan sebagai acuan dalam perhitungan pembangunan pemerintah, pengadaan barang dan jasa pemerintah, maka dari itu penulis ingin melakukan analisis perbandingan perhitungan Rencana Anggara Biaya menggunakan Metode SNI 2010 dan Analisis Harga Satuan Pekerjaan (AHSP) Bidang Cipta Karya Peraturan Menteri Pekerjaan Umum dan Perumahan Rakyat (PUPR) Nomor 28 Tahun 2016 yang bertujuan untuk mendapatkan harga total yang efisien, selain itu penulis ingin memperkenalkan peraturan Menteri Pekerjaan Umum dan Perumahan Rakyat (PUPR), agar mahasiswa Program Studi Teknik Sipil Fakukltas Teknik Universitas Kristen Palangka Raya pada khususnya, mampu mengaplikasikan peraturan ini.

Tujuan Penelitian yang ingin di capai adalah Mengetahui Rencana Anggaran Biaya (RAB) pada Pembangunan Gedung Kantor Pengadilan Tinggi Agama Banjarmasin Tahap II, untuk mengetahui perbandingan Rencana Anggaran Biaya (RAB) dalam pelaksanaan pekerjaan dengan menggunakan metode SNI 2010 dan Analisis Harga Satuan Pekerjaan (AHSP) Bidang Cipta Karya Peraturan Menteri PUPR Nomor 28 Tahun 2016.

\section{METODE PENELITIAN}

Penelitian ini dilakukan dengan Membandingan Rencana Anggaran Biaya Antara Metode SNI 2010 dan Analisis Harga Satuan Pekerjaan Pada Pekerjaan Pembangunan Gedung Kantor Pengadilan Tinggi Agama Banjarmasin Tahap II yang terletak di Kotamadya Banjarbaru, dengan alamat Jln. Aneka Tambang, Komplek Perkantoran Gubernur Kalimantan Selatan, Banjarbaru.Analisis Perbandingan Rencana Anggaran Biaya Menggunakan Metode SNI 2010 dan metode AHSP Bidang Cipta Karya Peraturan Menteri PUPR Nomor 28 Tahun 2016.

\section{HASIL DAN PEMBAHASAN}

Dalam Pekerjaan Pembangunan Gedung Kantor Pengadilan Tinggi Agama Banjarmasin Tahap II, daftar harga satuan bahan dan upah di kota banjarbaru tahun 2017 adalah sebagai berikut: 
JURNAL KACAPURI

JURNAL KEILMUAN TEKNIK SIPIL

Volume 4 Nomor 2 Edisi Desember 2021

Tabel 1. Daftar Harga Bahan dan Upah Kodya Banjarbaru Tahun 2017

\begin{tabular}{|c|c|c|c|c|c|c|c|c|c|c|}
\hline \multirow{2}{*}{ No. } & \multirow{2}{*}{ NAMA BAHAN } & \multirow{2}{*}{ SATUAN } & \multirow{2}{*}{\multicolumn{2}{|c|}{$\begin{array}{c}\text { HARGA SATUAN } \\
(\mathbb{R p})\end{array}$}} & \multirow{2}{*}{ KETERANGAN } & \multirow{2}{*}{\multicolumn{2}{|c|}{\begin{tabular}{l|l}
26 & Mur \\
27 & Paku Imacam-macaml \\
\end{tabular}}} & \multirow{2}{*}{$\frac{\mathrm{pCs}}{\mathrm{Kg}}$} & \multirow{2}{*}{$\begin{array}{lr}\text { Rp } & 500,00 \\
R p & 26.565,00 \\
\end{array}$} & \\
\hline & & & & & & & & & & \\
\hline $\mathrm{A}$ & UPAH KERJA & & & & & 28 & Paku Ramset & $\mathrm{kg}$ & $2.900,00$ & \\
\hline 1 & Pekerja & h.o & $\mathrm{Rp}$ & $91.500,00$ & & 29 & Papan Kayu Kelas III Setara Lanan & $\mathrm{m} 3$ & $\operatorname{Rp} \quad 2.922 .150,00$ & \\
\hline 2 & Tukang & h.o & $\mathrm{Rp}$ & $131.560,00$ & & 30 & Pasir Beton & $\mathrm{m} 3$ & $226.100,48$ & \\
\hline 3 & Kepala tukang & h.o & $\mathrm{Rp}$ & $171.600,00$ & & 31 & Pasir pasang & $\mathrm{m} 3$ & $226.100,48$ & \\
\hline 4 & Mandor & h.o & $\operatorname{Rp}$ & $157.300,00$ & & 32 & Pasir urug & $\mathrm{m} 3$ & $179.031,24$ & \\
\hline 5 & Operator & h.o & $\mathrm{Rp}$ & $253.970,00$ & & 32 & Pedestal Set & pcs & $55.000,00$ & \\
\hline 6 & Supir & h.o & $\mathrm{Rp}$ & $151.580,00$ & & 32 & Pipa besi Kotak Hollow 40.20 & $\mathrm{~m}^{\prime}$ & $11.458,33$ & \\
\hline 7 & Pembantu supir & h.o & Rp & $94.380,00$ & & 33 & Pipa besi Kotak Hollow 40.20 & $\mathrm{btg}$ & $68.750,00$ & \\
\hline 8 & Mekanik & h.o & $\mathrm{Rp}$ & $243.100,00$ & & 34 & Pipa besi Kotak Hollow 40.20 & $\mathrm{~kg}$ & $4.583,33$ & \\
\hline$B$ & BAHAN/MATERIAL & & & & & 35 & Pipa besi Kotak Hollow 40.40 & $\mathrm{btg}$ & $93.750,00$ & \\
\hline 1 & Atap Enameld (Enameld Akrilik) & $\mathrm{m} 2$ & $\mathrm{Rp}$ & $1.150 .000,00$ & & 36 & Pipa besi Kotak Hollow 40.40 & $\mathrm{~kg}$ & $6.250,00$ & \\
\hline 2 & Baja Profil IWF (Baja Struktur) & $\mathrm{Kg}$ & $\mathrm{Rp}$ & $46.000,00$ & & 41 & Pipa galvanis dimeter 11/2" + biaya transport & $\mathrm{m}$ & $21.666,67$ & \\
\hline 3 & Balok kayu kelas III & $\mathrm{m} 3$ & Rp & $1.992 .375,00$ & & 42 & Pipa galvanis dimeter 1" + biaya transport & $\mathrm{m}$ & $14.166,67$ & \\
\hline 4 & Bata merah & bh & Rp & 845,25 & & 43 & Pipa galvanis dimeter $3 / 4^{\prime \prime}+$ biaya transport & $\mathrm{m}$ & $11.666,67$ & \\
\hline 5 & Besi beton polos & $\mathrm{Kg}$ & Rp & $15.787,20$ & & 45 & Pipa PVC 1 1/2" & $\mathrm{m}$ & $24.500,00$ & \\
\hline 6 & Besi Canal C & $\mathrm{Kg}$ & Rp & $19.450,00$ & & 46 & Pipa PVC 1" & $\mathrm{m}$ & $15.500,00$ & \\
\hline 7 & Cat menie kayu & $\mathrm{Kg}$ & Rp & $41.250,00$ & & 47 & Pipa PVC 3" & $\mathrm{m}$ & $58.500,00$ & \\
\hline 8 & Cat minyak & $\mathrm{Kg}$ & Rp & $22.283,10$ & & 48 & Pipa PVC 4" & $\mathrm{m}$ & $85.500,00$ & \\
\hline 9 & Cat Tembok (Cat dasar) & $\mathrm{Kg}$ & Rp & $32.000,00$ & & 49 & Plamir & $\mathrm{Kg}$ & $56.317,80$ & \\
\hline 10 & Cat Tembok (Eksterior) & $\mathrm{Kg}$ & $\mathrm{Rp}$ & $123.500,00$ & & 50 & Plat Tumpuan Panel 1,6 mm (Uk, 100x120) & pcs & $3.000,00$ & \\
\hline 11 & Cat Tembok (Interior) & $\mathrm{Kg}$ & Rp & $98.800,00$ & & 51 & Plat Zincalume $0,35 \mathrm{~mm}$ & $\mathrm{lbr}$ & $81.250,00$ & \\
\hline 12 & Cat incromate & $\mathrm{Kg}$ & Rp & $62.500,00$ & & 52 & Plywood $9 \mathrm{~mm}$ & $\mathrm{lbr}$ & $175.770,00$ & \\
\hline 13 & Closet duduk Setara Toto & Set & Rp & $2.264 .666,00$ & & 53 & Pompa Submersible 1 ltr/dtk & $\mathrm{m}$ & $\operatorname{Rp} \quad 39.600 .000,00$ & \\
\hline 14 & Compoun & zak & Rp & $907,600,00$ & & 54 & Prime Coating & ltr & $39.500,00$ & \\
\hline 15 & Cotton Plester & bh & Rp & $29,600,00$ & & 55 & Roll Rangka & $\mathrm{kg}$ & $4.500,00$ & \\
\hline 16 & Dolken dia. $8-10 / 400 \mathrm{~cm}$ & $\frac{11}{b+g}$ & $\frac{\mathrm{R}}{\mathrm{Rn}}$ & 1036000 & & 56 & Screw & set & 500,00 & \\
\hline 17 & Elektroda |kawat las & $\frac{V_{0}}{\mathrm{de}}$ & $\frac{\pi p}{D_{n}}$ & $\frac{30.900,90}{20,240,00}$ & & 57 & Sekrup & $\mathrm{Kg}$ & $46.250,00$ & \\
\hline 11 & Gunsum & $\frac{h_{9}}{1 h e}$ & $\frac{\pi p}{p_{n}}$ & $20.240,00$ & & 58 & Semen Portland & $\mathrm{Kg}$ & $1.976,92$ & \\
\hline$\frac{18}{18}$ & Gypsum board l200 mm x $2400 \mathrm{~mm} \times \mathrm{y} \mathrm{mm}$ & lor & $\frac{\mathrm{Kp}}{\mathrm{P}_{\mathrm{n}}}$ & $216.119,00$ & & 59 & Semen Portland $50(\mathrm{Kg})$ & Zak & $99.245,00$ & \\
\hline 18 & Kalsi board $1200 \mathrm{~m} \times 2400 \mathrm{~mm} \times 5 \mathrm{~mm}$ & lbr & Rp & $103.845,00$ & & 60 & Semen warna & $\mathrm{Kg}$ & $1.984,90$ & \\
\hline 19 & Kawat beton & $\mathrm{Kg}$ & Rp & $27.232,92$ & & 61 & Semen warna $(50 \mathrm{~kg})$ & Zak & $99.245,00$ & \\
\hline 19 & Kayu Profil dim. $5 \mathrm{~cm}$ & $\mathrm{~m}^{\prime}$ & Rp & $11.350,50$ & & 62 & Septic Tank $3 \mathrm{~m} 3$ & $\mathrm{bh}$ & $\operatorname{Rp} \quad 11.323 .331,00$ & \\
\hline 20 & Kerikil & $\mathrm{m} 3$ & Rp & $199.056,00$ & & 63 & Tegel/ keramik 30x30 polos putih (11 pcs/pak) & bh & $10.626,00$ & \\
\hline 20 & Lapisan Galranis & $\mathrm{kg}$ & Rp & $6.000,00$ & & 64 & Ubin Granite tile $60 \times 60$ setara granito & bh & $143,873,63$ & \\
\hline 21 & LPG $3 \mathrm{~kg}$ & buah & $\mathrm{Rp}$ & $200,000,00$ & & 65 & U-Bolt & pcs & $5.300,00$ & \\
\hline 22 & Membrane & $\mathrm{m} 2$ & $\mathrm{Rp}$ & $64.000,00$ & & 66 & Urinoir Setara Toto & buah & $945,000,00$ & \\
\hline 23 & Meni Besi & $\mathrm{Kg}$ & $\mathrm{Rp}$ & $35.000,00$ & & 67 & Valve Air 11/2" & $\mathrm{m}$ & $57,480,00$ & \\
\hline 24 & Minyak bekisting & Itr & $\mathrm{Rp}$ & $10.263,00$ & & 68 & Valve Air 1" & $\mathrm{m}$ & $40.680,00$ & \\
\hline 25 & Minyak cat & $\mathrm{Kg}$ & $\mathrm{Rp}$ & $27.500,00$ & & 69 & Washtafel Setara Toto & buah & $620.957,00$ & \\
\hline
\end{tabular}

Sumber: Standar Satuan Harga Barang dan Jasa Kodya Banjarbaru Tahun 2017 
JURNAL KACAPURI

JURNAL KEILMUAN TEKNIK SIPIL Volume 4 Nomor 2 Edisi Desember 2021

Tabel 2. Rekapitulasi Rencana Anggaran Biaya Metode SNI 2010

\begin{tabular}{|c|c|c|c|}
\hline \multicolumn{2}{|r|}{ URAIAN PEKERJAAN } & \multicolumn{2}{|r|}{ JUMLAH } \\
\hline \multirow[t]{3}{*}{ A } & PEKERJAAN STRUKTUR & \multirow[b]{2}{*}{$\mathrm{Rp}$} & \multirow[b]{2}{*}{$2.977 .186 .029,42$} \\
\hline & I $\quad$ PEK. STRUKTUR RANGKA ATAP & & \\
\hline & II PEK. STRUKTUR BETON & $\mathrm{Rp}$ & $14.375 .615,38$ \\
\hline \multicolumn{2}{|r|}{ JUMLAH PEKERJAAN STRUKTUR } & $\mathbf{R p}$ & $2.991 .561 .644,81$ \\
\hline \multirow[t]{9}{*}{ B } & PEKERJAAN ARSITEKTUR & & \\
\hline & LANTAI 1 & & \\
\hline & I $\quad$ PEKERJAAN PERSIAPAN & $\mathrm{Rp}$ & $4.500 .000,00$ \\
\hline & II PEKERJAAN PASANGAN DINDING + PLESTERAN + ACIAN & $\mathrm{Rp}$ & $1.044 .674 .438,57$ \\
\hline & III PEKERJAAN LANTAI \& DINDING KERAMIK & $\mathrm{Rp}$ & $517.737 .913,20$ \\
\hline & IV $\quad$ PEKERJAAN PINTU DAN JENDELA & $\mathrm{Rp}$ & $95.700 .000,00$ \\
\hline & V $\quad$ PEKERJAAN PLAFOND & $\mathrm{Rp}$ & $312.201 .651,15$ \\
\hline & VI PEKERJAAN PENGECATAN & $\mathrm{Rp}$ & $467.509 .879,13$ \\
\hline & VII $\quad$ PEKERJAAN SECONDARY SKIN, ACCESSORY & $\mathrm{Rp}$ & $16.300 .000,00$ \\
\hline \multicolumn{2}{|r|}{ JUMLAH PEKERJAAN ARSITEKTUR LANTAI 1} & $\mathbf{R p}$ & $2.458 .623 .882,05$ \\
\hline & LANTAI 2 & & \\
\hline & $\begin{array}{ll}\text { I } & \text { PEKERJAAN PASANGAN DINDING } \\
\end{array}$ & $\mathrm{Rp}$ & $1.149 .721 .165,11$ \\
\hline & II $\quad$ PEKERJAAN LANTAI \& DINDING KERAMIK & $\mathrm{Rp}$ & $471.330 .824,89$ \\
\hline & III $\quad$ PEKERJAAN PINTU DAN JENDELA & $\mathrm{Rp}$ & $90.700 .000,00$ \\
\hline & IV $\quad$ PEKERJAAN PLAFOND & $\mathrm{Rp}$ & $365.610 .010,13$ \\
\hline & V $\quad$ PEKERJAAN PENGECATAN & $\mathrm{Rp}$ & $502.292 .788,70$ \\
\hline & $\begin{array}{ll}\text { VI } & \text { PEKERJAAN PENUTUP ATAP }\end{array}$ & $\mathrm{Rp}$ & $3.709 .846 .649,37$ \\
\hline \multicolumn{2}{|r|}{$\begin{array}{l}\text { JUMLAH PEKERJAAN ARSITEKTUR LANTAI } 2 \\
\end{array}$} & $\mathbf{R p}$ & $6.289 .501 .438,19$ \\
\hline \multicolumn{2}{|r|}{ JUMLAH PEKERJAAN ARSITEKTUR } & $\mathbf{R p}$ & $8.748 .125 .320,23$ \\
\hline \multirow[t]{3}{*}{$\mathbf{C}$} & PEKERJAAN INTERIOR \& ACP & & \\
\hline & I $\quad$ PEKERJAAN ACP & $\mathrm{Rp}$ & $120.250 .000,00$ \\
\hline & II $\quad$ PEKERJAAN INTERIOR & $\mathrm{Rp}$ & $64.272 .000,00$ \\
\hline \multicolumn{2}{|r|}{ JUMLAH PEKERJAAN INTERIOR \& ACP } & $\mathbf{R p}$ & $184.522 .000,00$ \\
\hline \multirow[t]{10}{*}{ D } & PEKERJAAN MEKANIKAL ELEKTRIKAL PLUM BING \& IT & & \\
\hline & I $\quad$ PEKERJAAN PENYAMBUNGAN DAYA LISTRIK & $\mathrm{Rp}$ & $95.630 .000,00$ \\
\hline & II $\quad$ PEKERJAAN AC & $\mathrm{Rp}$ & $2.819 .006 .000,00$ \\
\hline & III $\quad$ PEKERJAAN LISTRIK \& PLUMBING & $\mathrm{Rp}$ & $703.241 .084,25$ \\
\hline & IV PEKERJAAN IT & $\mathrm{Rp}$ & $1.094 .241 .000,00$ \\
\hline & JUMLAH PEKERJAAN MEP DAN IT & $\mathbf{R p}$ & 4.712.118.084,25 \\
\hline & JUMLAH TOTAL & $\mathbf{R p}$ & $16.636 .327 .049,29$ \\
\hline & (OVERHEAD + PROFIT 15\%) & $\mathbf{R p}$ & $2.495 .449 .057,39$ \\
\hline & JUMLAH TOTAL + (OVERHEAD + PROFIT 15\%) & $\mathbf{R p}$ & $19.131 .776 .106,68$ \\
\hline & DIBULATKAN & $\mathbf{R p}$ & $19.131 .000 .000,00$ \\
\hline
\end{tabular}

Sumber: Hasil Analisis

Untuk Rencana Anggaran Biaya dengan menggunakan Metode SNI 2010 terbagi menjadi 4 (empat) bidang pekerjaan, daftar Rencana Anggaran Biaya dan dapat di lihat pada tabel di bawah ini. 
JURNAL KACAPURI

JURNAL KEILMUAN TEKNIK SIPIL

Volume 4 Nomor 2 Edisi Desember 2021

Tabel 3. Daftar Rencana Anggaran Biaya Metode SNI 2010 Bidang Pekerjaan Struktur

\begin{tabular}{|c|c|c|c|c|c|c|c|c|}
\hline \multirow{2}{*}{ No } & \multirow{2}{*}{$\begin{array}{c}\text { URAIAN PEKERJAAN } \\
\mathrm{b}\end{array}$} & \multirow[t]{2}{*}{ Analisis } & \multirow{2}{*}{$\frac{\text { SAT }}{\mathrm{c}}$} & \multirow{2}{*}{\begin{tabular}{|c|} 
VOLUME \\
$\mathrm{d}$ \\
\end{tabular}} & \multicolumn{2}{|c|}{$\begin{array}{c}\text { HARGA } \\
\text { SATUAN( Rp.) }\end{array}$} & \multicolumn{2}{|c|}{ JUM LAH HARGA (Rp.) } \\
\hline & & & & & & $\mathrm{e}$ & & $\mathrm{f}$ \\
\hline & & & & & & & & \\
\hline I & PEK. STRUKTUR RANGKA ATAP & & & & & & & \\
\hline A & PEK. ATAP BAJA & & & & & & & \\
\hline 1 & Pek. Baja IWF 350x350x12x19mm & $6 . \mathrm{a}$ & $\mathrm{Kg}$ & 17894,34 & $\mathrm{Rp}$ & $60.756,2$ & $\mathrm{Rp}$ & 1.087.191.005,1 \\
\hline 2 & Pek. Baja IWF 200x100x5.5x8 mm & $6 . a$ & $\mathrm{Kg}$ & 1711,17 & $\mathrm{Rp}$ & $60.756,2$ & $\mathrm{Rp}$ & $103.963 .831,1$ \\
\hline 3 & Pek. Baja IWF 250x125x6x9 mm & $6 . a$ & $\mathrm{Kg}$ & 1319,73 & $\mathrm{Rp}$ & $60.756,2$ & $\mathrm{Rp}$ & $80.181 .490,4$ \\
\hline 4 & Pek. Baja IWF 300x150x6.5x9 mm & $6 . \mathrm{a}$ & $\mathrm{Kg}$ & 2256,30 & $\mathrm{Rp}$ & $60.756,2$ & $\mathrm{Rp}$ & $137.084 .096,9$ \\
\hline 5 & Pek. Baja IWF 350x175x7x11 mm & $6 . \mathrm{a}$ & $\mathrm{Kg}$ & 18771,82 & $\mathrm{Rp}$ & $60.756,2$ & $\mathrm{Rp}$ & $1.140 .503 .485,0$ \\
\hline 6 & Pek. Baja IWF 400x200x8x13 mm & $6 . a$ & $\mathrm{Kg}$ & 2058,02 & $\mathrm{Rp}$ & $60.756,2$ & $\mathrm{Rp}$ & $125.037 .094,7$ \\
\hline 7 & Pek. Baja C 125.50.20.2,3 & $6 . b$ & $\mathrm{Kg}$ & 7036,34 & $\mathrm{Rp}$ & $31.985,7$ & $\mathrm{Rp}$ & $225.061 .890,1$ \\
\hline 8 & Pek. Base Plate & - & $\mathrm{Kg}$ & 991,23 & $\mathrm{Rp}$ & $27.705,0$ & $\mathrm{Rp}$ & $27.461 .892,8$ \\
\hline 9 & Pek. Pasang mur - baut & - & bh & 2184,09 & $\mathrm{Rp}$ & $10.500,0$ & $\mathrm{Rp}$ & $22.932 .933,0$ \\
\hline 10 & Pek. Pasang ikatan angin & - & $\mathrm{Kg}$ & 509,52 & $\mathrm{Rp}$ & $15.612,0$ & $\mathrm{Rp}$ & $7.954 .658,8$ \\
\hline 11 & Pek. Pasang angkur & - & bh & 295,95 & $\mathrm{Rp}$ & $62.000,0$ & $\mathrm{Rp}$ & $18.348 .714,0$ \\
\hline \multirow[t]{2}{*}{12} & Pek. Pasang jarum keras & - & bh & 44,39 & $\mathrm{Rp}$ & $33.000,0$ & $\mathrm{Rp}$ & $1.464 .937,7$ \\
\hline & & & & & \multicolumn{2}{|c|}{ SUB TOTAL A } & $\mathrm{Rp}$ & 2.977.186.029,4 \\
\hline II & PEK. STRUKTUR BETON & & & & & & & \\
\hline \multirow[t]{2}{*}{$\mathrm{A}$} & LANTAI 1 & & & & & & & \\
\hline & \multicolumn{3}{|c|}{ PEKERJAAN BETON, BEKISTING \& PEM BESIAN } & & & & & \\
\hline 1 & Pek. Beton Kolom 15/15 & $1 . \mathrm{a}$ & $\mathrm{m} 3$ & 6,03 & & $.123 .757,56$ & & $6.776 .258,11$ \\
\hline 2 & Pek. Bekisting Kolom & $1 . b$ & $\mathrm{~m} 2$ & 0,27 & & $319.162,93$ & & $86.812,32$ \\
\hline \multirow[t]{2}{*}{3} & Pek. Pembesian Kolom & $1 . c$ & $\mathrm{Kg}$ & 3,56 & & $20.219,57$ & & $71.891,82$ \\
\hline & & & & & \multicolumn{2}{|c|}{ SUB TOTAL II - A } & & $6.934 .962,24$ \\
\hline \multirow[t]{2}{*}{ B } & LANTAI 2 & & & & & & & \\
\hline & \multicolumn{3}{|c|}{ PEKERJAAN BETON, BEKISTING \& PEM BESIAN } & & & & & \\
\hline 1 & Pek. Beton Kolom 15/15 & 1.a & $\mathrm{m} 3$ & 6,48 & $\mathrm{Rp}$ & $.123 .757,56$ & $\mathrm{Rp}$ & $7.281 .949,01$ \\
\hline 2 & Pek. Bekisting Kolom & 1.b & $\mathrm{m} 2$ & 0,27 & $\mathrm{Rp}$ & $319.162,93$ & $\mathrm{Rp}$ & $86.812,32$ \\
\hline 3 & Pek. Pembesian Kolom & $1 . c$ & $\mathrm{Kg}$ & 3,56 & \multirow{2}{*}{\multicolumn{2}{|c|}{\begin{tabular}{|l|l}
$\mathrm{RP}$ & $20.219,01$ \\
SUB TOTAL II $-\mathrm{B}$ & 1 \\
\end{tabular}}} & $\mathrm{Rp}$ & $71.891,82$ \\
\hline & & & & & & & $\mathrm{Rp}$ & $7.440 .653,14$ \\
\hline \multicolumn{7}{|c|}{ SUB TOTAL II - $(A+B)$} & $\mathrm{Rp}$ & $14.375 .615,38$ \\
\hline
\end{tabular}

Sumber: Hasil Analisis 
JURNAL KACAPURI

JURNAL KEILMUAN TEKNIK SIPIL Volume 4 Nomor 2 Edisi Desember 2021

Tabel 4. Daftar Rencana Anggaran Biaya Metode SNI 2010 Bidang Pekerjaan Arsitektur

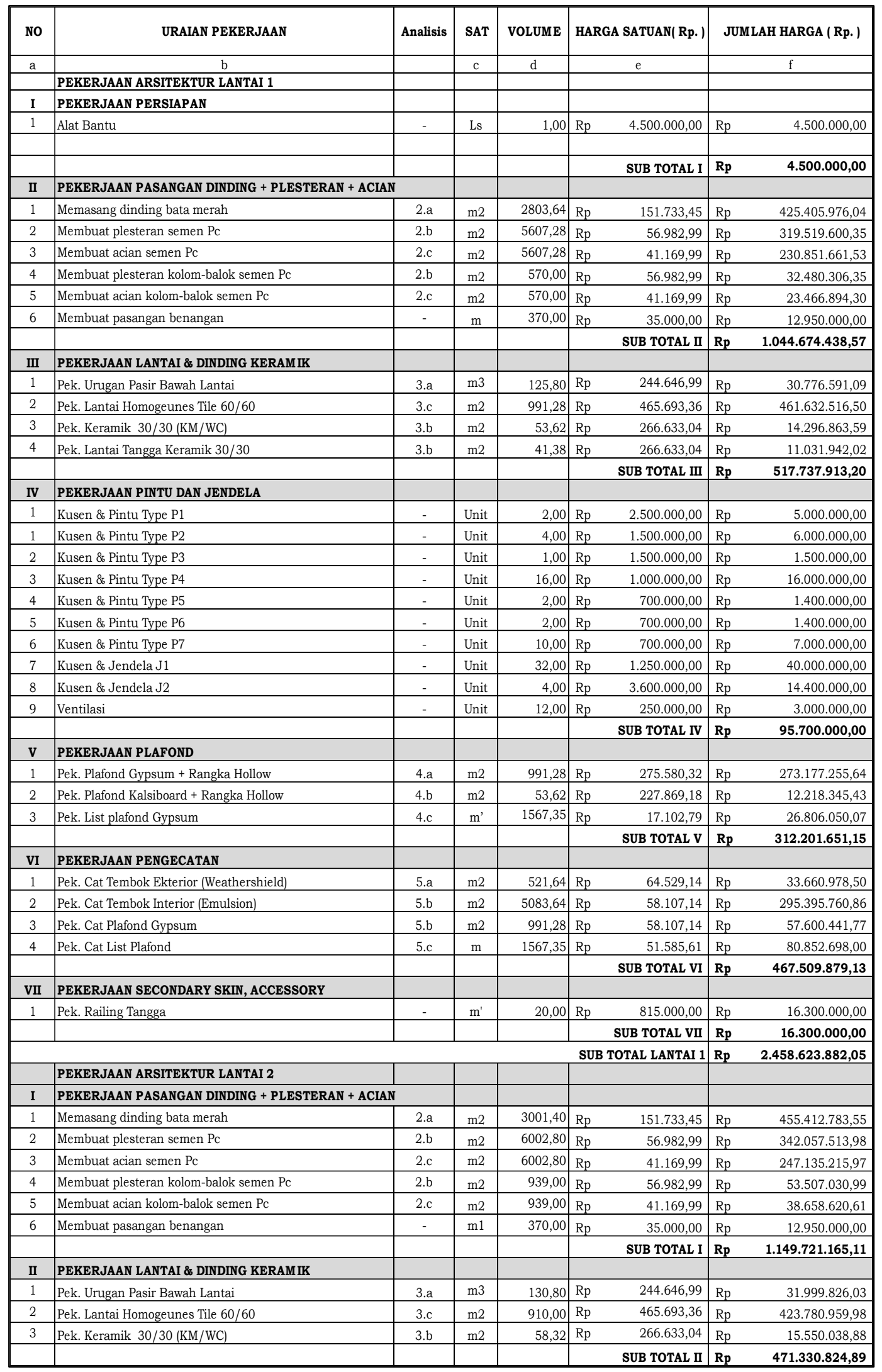


JURNAL KACAPURI

JURNAL KEILMUAN TEKNIK SIPIL Volume 4 Nomor 2 Edisi Desember 2021

\begin{tabular}{|c|c|c|c|c|c|c|c|c|}
\hline III & PEKERJAAN PINTU DAN JENDELA & & & & & & & \\
\hline 2 & Kusen \& Pintu Type P2 & - & Unit & 4,00 & $\mathrm{Rp}$ & $1.500 .000,00$ & $\mathrm{Rp}$ & $6.000 .000,00$ \\
\hline 3 & Kusen \& Pintu Type P3 & - & Unit & 1,00 & $\mathrm{Rp}$ & $1.500 .000,00$ & $\mathrm{Rp}$ & $1.500 .000,00$ \\
\hline 4 & Kusen \& Pintu Type P4 & - & Unit & 16,00 & $\mathrm{Rp}$ & $1.000 .000,00$ & $\mathrm{Rp}$ & $16.000 .000,00$ \\
\hline 5 & Kusen \& Pintu Type P5 & - & Unit & 2,00 & $\mathrm{Rp}$ & $700.000,00$ & $\mathrm{Rp}$ & $1.400 .000,00$ \\
\hline 6 & Kusen \& Pintu Type P6 & - & Unit & 2,00 & $\mathrm{Rp}$ & $700.000,00$ & $\mathrm{Rp}$ & $1.400 .000,00$ \\
\hline 7 & Kusen \& Pintu Type P7 & - & Unit & 10,00 & $\mathrm{Rp}$ & $700.000,00$ & $\mathrm{Rp}$ & $7.000 .000,00$ \\
\hline 8 & Kusen \& Jendela J1 & - & Unit & 32,00 & $\mathrm{Rp}$ & $1.250 .000,00$ & $\mathrm{Rp}$ & $40.000 .000,00$ \\
\hline 9 & Kusen \& Jendela J2 & - & Unit & 4,00 & $\mathrm{Rp}$ & $3.600 .000,00$ & $\mathrm{Rp}$ & $14.400 .000,00$ \\
\hline 10 & Ventilasi & - & Unit & 12,00 & $\mathrm{Rp}$ & $250.000,00$ & $\mathrm{Rp}$ & $3.000 .000,00$ \\
\hline & & & & & & SUB TOTAL III & $\mathrm{Rp}$ & $90.700 .000,00$ \\
\hline IV & PEKERJAAN PLAFOND & & & & & & & \\
\hline 1 & Pek. Plafond Gypsum+ Rangka Hollow & 4.a & $\mathrm{m} 2$ & 1175,20 & $\mathrm{Rp}$ & $275.580,32$ & $\mathrm{Rp}$ & $323.861 .987,36$ \\
\hline 2 & Pek. Plafond Kalsiboard + Rangka Hollow & 4.b & $\mathrm{m} 2$ & 58,32 & $\mathrm{Rp}$ & $227.869,18$ & $\mathrm{Rp}$ & $13.289 .330,58$ \\
\hline 3 & Pek. List plafond Gypsum & 4.c & $\mathrm{m}^{\prime}$ & 1663,98 & $\mathrm{Rp}$ & $17.102,79$ & $\mathrm{Rp}$ & $28.458 .692,18$ \\
\hline & & & & & & SUB TOTAL IV & $\mathrm{Rp}$ & $365.610 .010,13$ \\
\hline v & PEKERJAAN PENGECATAN & & & & & & & \\
\hline 1 & Pek. Cat Tembok Ekterior (Weathershield) & 5.a & $\mathrm{m} 2$ & 496,80 & $\mathrm{Rp}$ & $64.529,14$ & $\mathrm{Rp}$ & $32.058 .074,76$ \\
\hline 2 & Pek. Cat Tembok Interior (Emulsion) & 5.b & $\mathrm{m} 2$ & 5506,00 & $\mathrm{Rp}$ & $58.107,14$ & $\mathrm{Rp}$ & $319.937 .890,82$ \\
\hline 3 & Pek. Cat Plafond & $5 . b$ & $\mathrm{~m} 2$ & 1109,32 & $\mathrm{Rp}$ & $58.107,14$ & $\mathrm{Rp}$ & $64.459 .408,11$ \\
\hline 4 & Pek. Cat List Plafond & 5.c & $\mathrm{m}$ & 1663,98 & $\mathrm{Rp}$ & $51.585,61$ & $\mathrm{Rp}$ & $85.837 .415,01$ \\
\hline & & & & & & SUB TOTAL V & $\mathrm{Rp}$ & $502.292 .788,70$ \\
\hline VI & PEKERJAAN ATAP & & & & & & & \\
\hline 1 & Pasang Lapisan kedap air & $6 . c$ & $\mathrm{~m} 2$ & 1676,5398 & $\mathrm{Rp}$ & $248.745,35$ & $\mathrm{Rp}$ & 417.031.470,72 \\
\hline 2 & Pasang Rangka Primer & $6 . d$ & $\mathrm{~kg}$ & 3935,9965 & $\mathrm{Rp}$ & $25.888,77$ & $\mathrm{Rp}$ & $101.898 .093,72$ \\
\hline 3 & Pasang Rangka Sekunder Panel & $6 . e$ & $\mathrm{~kg}$ & 9982,1937 & $\mathrm{Rp}$ & $26.636,22$ & $\mathrm{Rp}$ & $265.887 .873,16$ \\
\hline 4 & Pasang Plat Tumpuan Panel & 6.f & Pcs & 12416,97 & $\mathrm{Rp}$ & $10.649,75$ & $\mathrm{Rp}$ & $132.237 .595,22$ \\
\hline 5 & Pasang Plat Tumpuan Sekunder $\&$ Braket & $6 . \mathrm{g}$ & Pcs & 9312 & $\mathrm{Rp}$ & $23.389,75$ & $\mathrm{Rp}$ & $217.805 .328,72$ \\
\hline 5 & Pasang Pedestal & $6 . \mathrm{h}$ & Pcs & 533,5 & $\mathrm{Rp}$ & $85.491,16$ & $\mathrm{Rp}$ & 45.609.531,19 \\
\hline 6 & Pasang Penutup Atap Ornamental & $6 . \mathrm{i}$ & $\mathrm{m} 2$ & 1867,25 & $\mathrm{Rp}$ & $1.354 .599,95$ & $\mathrm{Rp}$ & $2.529 .376 .756,64$ \\
\hline & & & & & & SUB TOTAL VI & Rp & $3.709 .846 .649,37$ \\
\hline \multicolumn{7}{|c|}{ SUB TOTAL LANTAI 2} & $\mathrm{Rp}$ & $6.289 .501 .438,19$ \\
\hline \multicolumn{7}{|c|}{ JUMLAH TOTAL PEKERJAAN ARSITEKTUR } & $\mathrm{Rp}$ & 8.748.125.320,23 \\
\hline
\end{tabular}

Sumber: Hasil Analisis

Tabel 5. Daftar Rencana Anggaran Biaya Metode SNI 2010 Bidang Pekerjaan Interior dan ACP

\begin{tabular}{|c|c|c|c|c|c|c|}
\hline No & URAIAN PEKERJAAN & Analisis & SAT & VOLUME & $\begin{array}{c}\text { HARGA } \\
\text { SATUAN( Rp.) }\end{array}$ & JUMLAH HARGA ( Rp. ) \\
\hline \multirow[t]{2}{*}{$\mathrm{a}$} & $\mathrm{b}$ & & $\mathrm{c}$ & $\mathrm{d}$ & $\mathrm{e}$ & f \\
\hline & PEKERJAAN ACP \& INTERIOR & & & & & \\
\hline $\mathbf{I}$ & PEKERJAAN ACP & & & & & \\
\hline 1 & Pekerjaan ACP Depan & - & M2 & 22,5 & $\mathrm{Rp} \quad 1.250 .000$ & $28.125 .000,0$ \\
\hline 2 & Pekerjaan ACP Belakang & - & M2 & 22,5 & $\mathrm{Rp} \quad 1.250 .000$ & $28.125 .000,0$ \\
\hline 3 & Pekerjaan ACP Samping Kanan & - & M2 & 25,6 & $\mathrm{Rp} \quad 1.250 .000$ & $32.000 .000,0$ \\
\hline \multirow[t]{2}{*}{4} & Pekerjaan ACP Samping Kiri & - & M3 & 25,6 & 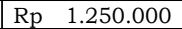 & $32.000 .000,0$ \\
\hline & & & & & SUB TOTAL I & $120.250 .000,0$ \\
\hline II & PEKERJAAN INTERIOR & & & & & \\
\hline 1 & Pekerjaan Pemasangan Finishing Teakwood Lt 01 & - & M2 & 414,80 & $80.000,0$ & $33.184 .000,0$ \\
\hline \multirow[t]{2}{*}{2} & Pekerjaan Pemasangan Finishing Teakwood Lt 02 & - & M2 & 388,60 & \begin{tabular}{|ll}
$\operatorname{Rp}$ & $80.000,0$ \\
\end{tabular} & $31.088 .000,0$ \\
\hline & & & & & SUB TOTAL II & $64.272 .000,0$ \\
\hline \multicolumn{6}{|c|}{ JUMLAH TOTAL PEKERJAAN ARSITEKTUR } & $184.522 .000,0$ \\
\hline
\end{tabular}

Sumber: RAB Kontraktor 
JURNAL KACAPURI

JURNAL KEILMUAN TEKNIK SIPIL Volume 4 Nomor 2 Edisi Desember 2021

Tabel 6. Daftar Rencana Anggaran Biaya Metode SNI 2010 Bidang Pekerjaan Mekanikal, Elektrikal, Plumbing dan IT

\begin{tabular}{|c|c|c|c|c|c|c|c|}
\hline \multirow{2}{*}{$\begin{array}{c}\text { No } \\
\mathrm{a} \\
\end{array}$} & URAIAN PEKERJAAN & \multirow[t]{2}{*}{$\begin{array}{c}\text { No. } \\
\text { Analisis }\end{array}$} & SAT & \multirow[t]{2}{*}{ VOLUME } & $\begin{array}{l}\text { HARGA SATUAN( } \\
\text { Rp. ) }\end{array}$ & \multicolumn{2}{|c|}{ JUMLAH HARGA ( Rp. ) } \\
\hline & $\mathrm{b}$ & & $\mathrm{c}$ & & $\mathrm{e}$ & & $\mathrm{f}$ \\
\hline \multirow[t]{3}{*}{ I } & PEKERJAAN PENYAM BUNGAN DAYA LISTRIK & & & & & & \\
\hline & & & & & & & \\
\hline & Pasang Baru Daya Listrik 131.000VA & & & & & & \\
\hline & BP \& UJL & - & VA & $131.000,00$ & 630,00 & $\mathrm{Rp}$ & $82.530 .000,00$ \\
\hline & Biaya pengurusan, Sertifikasi ( SLO ) $\&$ Energized & - & VA & $131.000,00$ & 100,00 & $\mathrm{Rp}$ & $13.100 .000,00$ \\
\hline \multicolumn{6}{|r|}{ SUB TOTAL I } & $\mathbf{R p}$ & $95.630 .000,00$ \\
\hline \multirow[t]{2}{*}{ II } & PEKERJAAN TATA UDARA & & & & & & \\
\hline & Peralatan Utama & & & & & & \\
\hline $\mathbf{A}$ & Lantai - 1 & & & & & & \\
\hline & Sistem - 1 & & & & & & \\
\hline 1 & Indoor unit Wall Mounted kap. $12.300 \mathrm{Btu} / \mathrm{h}$ & - & unit & 1,00 & Rp $14.800 .000,00$ & $\mathrm{Rp}$ & $14.800 .000,00$ \\
\hline 2 & Indoor unit Wall Mounted kap. $15.400 \mathrm{Btu} / \mathrm{h}$ & - & unit & 1,00 & Rp $15.804 .000,00$ & $\mathrm{Rp}$ & $15.804 .000,00$ \\
\hline 3 & Indoor unit Wall Mounted kap. $19.100 \mathrm{Btu} / \mathrm{h}$ & - & unit & 1,00 & Rp $\quad 18.417 .000,00$ & $\mathrm{Rp}$ & $18.417 .000,00$ \\
\hline 4 & Indoor unit Split duct kap. $54.600 \mathrm{Btu} / \mathrm{h}$ & - & unit & 1,00 & Rp $31.506 .000,00$ & $\mathrm{Rp}$ & $31.506 .000,00$ \\
\hline 5 & Indoor unit Split duct kap. $76.400 \mathrm{Btu} / \mathrm{h}$ & - & unit & 1,00 & $\begin{array}{ll}\mathrm{Rp} & 52.700 .000,00 \\
\end{array}$ & $\mathrm{Rp}$ & $52.700 .000,00$ \\
\hline 6 & Out door unit kap. $191.000 \mathrm{Btu} / \mathrm{h}$ & - & unit & 1,00 & Rp 203.643.000,00 & $\mathrm{Rp}$ & $203.643 .000,00$ \\
\hline & Sistem - 2 & & & & & & \\
\hline 7 & Indoor unit Wall Mounted kap. $9.600 \mathrm{Btu} / \mathrm{h}$ & - & unit & 1,00 & $\begin{array}{ll}\mathrm{Rp} & 14.125 .000,00 \\
\end{array}$ & $\mathrm{Rp}$ & $14.125 .000,00$ \\
\hline 8 & Indoor unit Wall Mounted kap. $12.300 \mathrm{Btu} / \mathrm{h}$ & - & unit & 1,00 & Rp $14.620 .000,00$ & $\mathrm{Rp}$ & $14.620 .000,00$ \\
\hline 9 & Indoor unit Wall Mounted kap. $19.100 \mathrm{Btu} / \mathrm{h}$ & - & unit & 1,00 & Rp $18.248 .000,00$ & $\mathrm{Rp}$ & $18.248 .000,00$ \\
\hline 10 & Indoor unit Split duct kap. $76.400 \mathrm{Btu} / \mathrm{h}$ & - & unit & 1,00 & $\begin{array}{ll}\mathrm{Rp} & 52.754 .000,00 \\
\end{array}$ & $\mathrm{Rp}$ & $52.754 .000,00$ \\
\hline 11 & Out door unit kap. $171.000 \mathrm{Btu} / \mathrm{h}$ & - & unit & 1,00 & Rp $183.252 .000,00$ & $\mathrm{Rp}$ & $183.252 .000,00$ \\
\hline 12 & Indoor + Outdoor unit Wall Mounted kap. $9.000 \mathrm{Btu} / \mathrm{h}$ & - & unit & 2,00 & $\begin{array}{ll}\mathrm{Rp} & 5.107 .000,00 \\
\end{array}$ & $\mathrm{Rp}$ & $10.214 .000,00$ \\
\hline 13 & Indoor + Outdoor unit Wall Mounted kap. $11.400 \mathrm{Btu} / \mathrm{h}$ & - & unit & 2,00 & $6.230 .000,00$ & $\mathrm{Rp}$ & $12.460 .000,00$ \\
\hline & & & & & SUB TOTAL II - A & $\mathbf{R p}$ & $642.543 .000,00$ \\
\hline B & Lantai - 2 & & & & & & \\
\hline & Sistem - 1 & & & & & & \\
\hline 1 & Indoor unit Wall Mounted kap. $12.300 \mathrm{Btu} / \mathrm{h}$ & - & unit & 2,00 & $\begin{array}{ll}\mathrm{Rp} & 14.620 .000,00 \\
\end{array}$ & $\mathrm{Rp}$ & $29.240 .000,00$ \\
\hline 2 & Indoor unit Wall Mounted kap. $15.400 \mathrm{Btu} / \mathrm{h}$ & - & unit & 1,00 & $\begin{array}{ll}\mathrm{Rp} & 15.804 .000,00 \\
\end{array}$ & $\mathrm{Rp}$ & $15.804 .000,00$ \\
\hline 3 & Indoor unit Wall Mounted kap. $19.100 \mathrm{Btu} / \mathrm{h}$ & - & unit & 2,00 & $\begin{array}{ll}\mathrm{Rp} & 18.248 .000,00 \\
\end{array}$ & $\mathrm{Rp}$ & $36.496 .000,00$ \\
\hline 4 & Indoor unit Wall Mounted kap. $24.200 \mathrm{Btu} / \mathrm{h}$ & - & unit & 1,00 & $\begin{array}{ll}\mathrm{Rp} & 19.551 .000,00 \\
\end{array}$ & $\mathrm{Rp}$ & $19.551 .000,00$ \\
\hline 5 & Indoor unit Split duct kap. $47.800 \mathrm{Btu} / \mathrm{h}$ & - & unit & 1,00 & $\begin{array}{ll}\mathrm{Rp} & 28.750 .000,00 \\
\end{array}$ & $\mathrm{Rp}$ & $28.750 .000,00$ \\
\hline 6 & Indoor unit Split duct kap. $95.500 \mathrm{Btu} / \mathrm{h}$ & - & unit & 1,00 & $\begin{array}{ll}\mathrm{Rp} & 58.775 .000,00 \\
\end{array}$ & $\mathrm{Rp}$ & $58.775 .000,00$ \\
\hline 7 & Out door unit kap. $290.000 \mathrm{Btu} / \mathrm{h}$ & - & unit & 1,00 & Rp 290.584.000,00 & $\mathrm{Rp}$ & $290.584 .000,00$ \\
\hline & Sistem - 2 & & & & & & \\
\hline 1 & Indoor unit Wall Mounted kap. $12.300 \mathrm{Btu} / \mathrm{h}$ & - & unit & 2,00 & $\begin{array}{ll}\mathrm{Rp} & 14.620 .000,00 \\
\end{array}$ & $\mathrm{Rp}$ & $29.240 .000,00$ \\
\hline 2 & Indoor unit Wall Mounted kap. $15.400 \mathrm{Btu} / \mathrm{h}$ & - & unit & 2,00 & $\mathrm{Rp} \quad 15.804 .000,00$ & $\mathrm{Rp}$ & $31.608 .000,00$ \\
\hline 3 & Indoor unit Wall Mounted kap. $19.100 \mathrm{Btu} / \mathrm{h}$ & - & unit & 2,00 & $\begin{array}{ll}\mathrm{Rp} & 18.248 .000,00 \\
\end{array}$ & $\mathrm{Rp}$ & $36.496 .000,00$ \\
\hline 4 & Indoor unit Wall Mounted kap. $24.200 \mathrm{Btu} / \mathrm{h}$ & - & unit & 1,00 & Rp $19.551 .000,00$ & $\mathrm{Rp}$ & $19.551 .000,00$ \\
\hline 5 & Indoor unit Split duct kap. $38.200 \mathrm{Btu} / \mathrm{h}$ & - & unit & 1,00 & $\begin{array}{ll}\mathrm{Rp} & 26.979 .000,00 \\
\end{array}$ & $\mathrm{Rp}$ & $26.979 .000,00$ \\
\hline 6 & Out door unit kap. $273.000 \mathrm{Btu} / \mathrm{h}$ & - & unit & 1,00 & Rp $279.675 .000,00$ & $\mathrm{Rp}$ & $279.675 .000,00$ \\
\hline & & & & & SUB TOTAL II - B & $\mathbf{R p}$ & $902.749 .000,00$ \\
\hline & INSTALASI TATA UDARA & & & & & & \\
\hline $\mathbf{c}$ & Lantai - 1 & & & & & & \\
\hline 1 & Instalasi pipa refrigerant lengkap isolasi $\varnothing 7 / 8^{\prime \prime}+15 / 8^{\prime \prime}$ & - & $\mathrm{m}^{1}$ & 172,00 & $526.000,00$ & $\mathrm{Rp}$ & $90.472 .000,00$ \\
\hline 2 & Instalasi pipa refrigerant lengkap isolasi $\varnothing 1 / 4^{\prime \prime}+1 / 2 "$ & - & $\mathrm{m}^{1}$ & 64,00 & $213.000,00$ & $\mathrm{Rp}$ & $13.632 .000,00$ \\
\hline 3 & Instalasi pipa refrigerant lengkap isolasi $\varnothing 1 / 4^{\prime \prime}+5 / 8^{\prime \prime}$ & - & $\mathrm{m}^{1}$ & 43,00 & $231.000,00$ & $\mathrm{Rp}$ & $9.933 .000,00$ \\
\hline 4 & Instalasi pipa refrigerant lengkap isolasi $\varnothing 3 / 8^{\prime \prime}+3 / 4 "$ & - & $\mathrm{m}^{1}$ & 51,00 & $260.000,00$ & $\mathrm{Rp}$ & $13.260 .000,00$ \\
\hline 5 & Instalasi pipa refrigerant lengkap isolasi $\varnothing 3 / 8^{\prime \prime}+5 / 8^{\prime \prime}$ & - & $\mathrm{m}^{1}$ & 37,00 & $245.000,00$ & $\mathrm{Rp}$ & $9.065 .000,00$ \\
\hline 6 & Instalasi pipa refrigerant lengkap isolasi $\varnothing 3 / 8^{\prime \prime}+3 / 4 "$ & - & $\mathrm{m}^{1}$ & 33,00 & $260.000,00$ & $\mathrm{Rp}$ & $8.580 .000,00$ \\
\hline 7 & Instalasi pipa refrigerant lengkap isolasi $\varnothing 5 / 8+11 / 8 "$ & - & $\mathrm{m}^{1}$ & 23,00 & $357.000,00$ & $\mathrm{Rp}$ & $8.211 .000,00$ \\
\hline 8 & Refnet joint & - & bh & 15,00 & $2.834 .000,00$ & $\mathrm{Rp}$ & $42.510 .000,00$ \\
\hline 9 & Instalasi kabel power dan kabel kontrol indoor & - & ttk & 30,00 & $1.486 .000,00$ & $\mathrm{Rp}$ & $44.580 .000,00$ \\
\hline 10 & Instalasi kabel power outdoor & - & ttk & 2,00 & $7.331 .000,00$ & $\mathrm{Rp}$ & $14.662 .000,00$ \\
\hline 11 & Instalasi pipa drain lengkap isolasi & - & ttk & 30,00 & $506.000,00$ & $\mathrm{Rp}$ & $15.180 .000,00$ \\
\hline 12 & $\begin{array}{l}\text { Instalasi ducting supply bahan BJLS, Glass wool, } \\
\text { Allumunium foil : }\end{array}$ & - & & & & & \\
\hline & ducting supply BJLS 50 & - & $\mathrm{m}^{2}$ & 158,00 & $469.000,00$ & $\mathrm{Rp}$ & $74.102 .000,00$ \\
\hline & ducting supply BJLS 60 & - & $\mathrm{m}^{2}$ & 77,00 & $541.000,00$ & $\mathrm{Rp}$ & $41.657 .000,00$ \\
\hline & ducting return BJLS 50 & - & $\mathrm{m}^{2}$ & 132,00 & $465.000,00$ & $\mathrm{Rp}$ & $61.380 .000,00$ \\
\hline & ducting return BJLS 60 & - & $\mathrm{m}^{2}$ & 58,00 & $543.000,00$ & $\mathrm{Rp}$ & $31.494 .000,00$ \\
\hline 13 & Flexible duct Ø 250 & - & $\mathrm{m}^{1}$ & 64,00 & $348.000,00$ & $\mathrm{Rp}$ & $22.272 .000,00$ \\
\hline 14 & Pan drain & - & bh & 3,00 & $1.177 .000,00$ & $\mathrm{Rp}$ & $3.531 .000,00$ \\
\hline 15 & Plenum supply dan return & - & bh & 6,00 & $3.901 .000,00$ & $\mathrm{Rp}$ & $23.406 .000,00$ \\
\hline 16 & Supply Air Diffuser 250 × 250 & - & bh & 22,00 & $422.000,00$ & $\mathrm{Rp}$ & $9.284 .000,00$ \\
\hline 17 & Return Air Grille 200 × 600 & - & bh & 12,00 & $568.000,00$ & $\mathrm{Rp}$ & $6.816 .000,00$ \\
\hline 18 & Pengisian freon R410 & - & lot & 1,00 & $\begin{array}{ll}\text { Rp } & 11.596 .000,00\end{array}$ & $\mathrm{Rp}$ & $11.596 .000,00$ \\
\hline 19 & Panel outdoor AC & - & unit & 1,00 & $\begin{array}{ll}\mathrm{Rp} & 18.700 .000,00 \\
\end{array}$ & $\mathrm{Rp}$ & $18.700 .000,00$ \\
\hline 20 & Pas. Kabel power NYY 4 × $10 \mathrm{~mm}^{2}$ & - & $\mathrm{m}^{\prime}$ & 200,00 & $113.000,00$ & $\mathrm{Rp}$ & $22.600 .000,00$ \\
\hline & & & & & SUB TOTAL II - C & $\mathbf{R p}$ & 596.923.000,00 \\
\hline
\end{tabular}


JURNAL KACAPURI

JURNAL KEILMUAN TEKNIK SIPIL

Volume 4 Nomor 2 Edisi Desember 2021

\begin{tabular}{|c|c|c|c|c|c|c|c|c|}
\hline D & Lantai - 2 & & & & & & & \\
\hline 1 & Instalasi pipa refrigerant lengkap isolasi $\varnothing 7 / 8 "+13 / 8 "$ & - & $\mathrm{m}^{1}$ & 144,00 & $\mathrm{Rp}$ & $526.000,00$ & Rp & $75.744 .000,00$ \\
\hline 2 & Instalasi pipa refrigerant lengkap isolasi Ø $1 / 4^{\prime \prime}+1 / 2 "$ & - & $\mathrm{m}^{1}$ & 72,00 & $\mathrm{Rp}$ & $213.000,00$ & Rp & $15.336 .000,00$ \\
\hline 3 & Instalasi pipa refrigerant lengkap isolasi Ø $1 / 4 "+5 / 8 "$ & - & $\mathrm{m}^{1}$ & 67,00 & $\mathrm{Rp}$ & $231.000,00$ & Rp & $15.477 .000,00$ \\
\hline 4 & Instalasi pipa refrigerant lengkap isolasi Ø $3 / 8 "+3 / 4 "$ & - & $\mathrm{m}^{1}$ & 44,00 & $\mathrm{Rp}$ & $260.000,00$ & Rp & $11.440 .000,00$ \\
\hline 5 & Instalasi pipa refrigerant lengkap isolasi $\varnothing 5 / 8 "+11 / 8$ & - & $\mathrm{m}^{1}$ & 27,00 & $\mathrm{Rp}$ & $357.000,00$ & $\mathrm{Rp}$ & $9.639 .000,00$ \\
\hline 6 & Refnet joint & - & bh & 15,00 & $\mathrm{Rp}$ & $3.270 .000,00$ & Rp & $49.050 .000,00$ \\
\hline 7 & Instalasi kabel power dan kabel kontrol indoor & - & ttk & 22,00 & $\mathrm{Rp}$ & $1.783 .000,00$ & $\mathrm{Rp}$ & $39.226 .000,00$ \\
\hline 8 & Instalasi kabel power outdoor & - & ttk & 2,00 & $\mathrm{Rp}$ & $10.181 .000,00$ & Rp & $20.362 .000,00$ \\
\hline 9 & Instalasi pipa drain lengkap isolasi & - & ttk & 22,00 & $\mathrm{Rp}$ & $506.000,00$ & $\mathrm{Rp}$ & $11.132 .000,00$ \\
\hline 10 & $\begin{array}{l}\text { Instalasi ducting supply bahan BJLS, Glass wool, } \\
\text { Allumunium foil : }\end{array}$ & - & & & & & & \\
\hline & ducting supply BJLS 50 & - & $\mathrm{m}^{2}$ & 253,00 & $\mathrm{Rp}$ & $469.000,00$ & Rp & $118.657 .000,00$ \\
\hline & ducting supply BJLS 60 & - & $\mathrm{m}^{2}$ & 94,00 & $\mathrm{Rp}$ & $541.000,00$ & $\mathrm{Rp}$ & $50.854 .000,00$ \\
\hline & ducting return BJLS 50 & - & $\mathrm{m}^{2}$ & 188,00 & $\mathrm{Rp}$ & $465.000,00$ & Rp & $87.420 .000,00$ \\
\hline & ducting return BJLS 60 & - & $\mathrm{m}^{2}$ & 76,00 & $\mathrm{Rp}$ & $543.000,00$ & $\mathrm{Rp}$ & $41.268 .000,00$ \\
\hline 13 & Flexible duct $\varnothing 250$ & - & $\mathrm{m}^{1}$ & 121,00 & $\mathrm{Rp}$ & $348.000,00$ & $\mathrm{Rp}$ & $42.108 .000,00$ \\
\hline 14 & Pan drain & - & bh & 6,00 & $\mathrm{Rp}$ & $1.177 .000,00$ & Rp & $7.062 .000,00$ \\
\hline 15 & Plenum supply dan return & - & bh & 12,00 & $\mathrm{Rp}$ & $3.901 .000,00$ & $\mathrm{Rp}$ & $46.812 .000,00$ \\
\hline 16 & Supply Air Diffuser 250 x 250 & - & $\mathrm{bh}$ & 32,00 & $\mathrm{Rp}$ & $422.000,00$ & $\mathrm{Rp}$ & $13.504 .000,00$ \\
\hline 17 & Return Air Grille 200 x 600 & - & bh & 18,00 & $\mathrm{Rp}$ & $568.000,00$ & $\mathrm{Rp}$ & $10.224 .000,00$ \\
\hline 18 & Pengisian freon R410 & - & lot & 1,00 & $\mathrm{Rp}$ & $11.476 .000,00$ & $\mathrm{Rp}$ & $11.476 .000,00$ \\
\hline & & & & & & & & \\
\hline & & & & & & UB TOTAL II - D & Rp & $676.791 .000,00$ \\
\hline & & & & SUB 7 & TOTA & $\mathrm{LII}(\mathrm{A}+\mathrm{B}+\mathrm{C}+\mathrm{D})$ & Rp & $2.819 .006 .000,00$ \\
\hline & & & & & & & & \\
\hline III & PEKERJAAN INSTALASI LISTRIK \& SANITASI & & & & & & & \\
\hline $\mathbf{A}$ & LISTRIK - LANTAI 1 & & & & & & & \\
\hline 1 & Pas. Stop Kontak Panasonic & - & $\mathrm{Bh}$ & 50,00 & $\mathrm{Rp}$ & $34.337,16$ & Rp & $1.716 .858,00$ \\
\hline 2 & Pas. Saklar Ganda Panasonic & - & $\mathrm{Bh}$ & 27,00 & $\mathrm{Rp}$ & $28.022,28$ & $\mathrm{Rp}$ & $756.601,64$ \\
\hline 3 & Pas. Saklar Tunggal Panasonic & - & $\mathrm{Bh}$ & 5,00 & $\mathrm{Rp}$ & $16.885,00$ & Rp & $84.425,00$ \\
\hline 4 & Pas. Lampu Down Light LED 9 Watt & - & $\mathrm{Bh}$ & 177,00 & $\mathrm{Rp}$ & $107.315,00$ & $\mathrm{Rp}$ & $18.994 .755,00$ \\
\hline 5 & Pas. Lampu Down Light LED $2 \times 9$ Watt & - & $\mathrm{Bh}$ & 14,00 & $\mathrm{Rp}$ & $214.630,00$ & Rp & $3.004 .820,00$ \\
\hline 6 & Pas. Lampu RM TL T5 1x28Watt & - & $\mathrm{Bh}$ & 14,00 & $\mathrm{Rp}$ & $889.000,00$ & $\mathrm{Rp}$ & $12.446 .000,00$ \\
\hline 7 & Pas. Lampu RM TL T5 2x28Watt & - & $\mathrm{Bh}$ & 15,00 & $\mathrm{Rp}$ & $1.106 .000,00$ & $\mathrm{Rp}$ & $16.590 .000,00$ \\
\hline 8 & Pas. Lampu Gantung & - & $\mathrm{Bh}$ & 1,00 & $\mathrm{Rp}$ & $1.068 .000,00$ & $\mathrm{Rp}$ & $1.068 .000,00$ \\
\hline 9 & Pas. Instalasi titik lampu & - & Ttk & 223,00 & $\mathrm{Rp}$ & $347.000,00$ & $\mathrm{Rp}$ & $77.381 .000,00$ \\
\hline 10 & Pas. Instalasi titik Stop kontak & - & Ttk & 50,00 & $\mathrm{Rp}$ & $377.000,00$ & $\mathrm{Rp}$ & $18.850 .000,00$ \\
\hline 11 & Pas. Panel Penerangan $\&$ Stopkontak Lt-1 & - & $\mathrm{Bh}$ & 1,00 & $\mathrm{Rp}$ & $17.639 .000,00$ & $\mathrm{Rp}$ & $17.639 .000,00$ \\
\hline 12 & Pas. Panel AC Lt-1 & - & $\mathrm{Bh}$ & 1,00 & $\mathrm{Rp}$ & $17.639 .000,00$ & $\mathrm{Rp}$ & $17.639 .000,00$ \\
\hline 13 & Pas. Panel LVMDP & - & $\mathrm{Bh}$ & 1,00 & $\mathrm{Rp}$ & $16.840 .000,00$ & $\mathrm{Rp}$ & $16.840 .000,00$ \\
\hline 14 & Pas. Panel Pompa Air Bersih & - & $\mathrm{Bh}$ & 1,00 & $\mathrm{Rp}$ & $7.621 .000,00$ & $\mathrm{Rp}$ & $7.621 .000,00$ \\
\hline 15 & Pas. Kabel power NYFGBY 4 × $120 \mathrm{~mm}^{2}$ LVMDP - PLN & - & $\mathrm{m}^{\prime}$ & 75,00 & $\mathrm{Rp}$ & $54.800,00$ & $\mathrm{Rp}$ & $4.110 .000,00$ \\
\hline 16 & 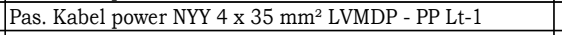 & - & $\mathrm{m}^{\prime}$ & 9,00 & $\mathrm{Rp}$ & $18.600,00$ & $R p$ & $167.400,00$ \\
\hline 17 & Pas. Kabel power NYY 4 × $50 \mathrm{~mm}^{2}$ LVMDP - PAC Lt- 1 & - & $\mathrm{m}^{\prime}$ & 9,00 & $\mathrm{Rp}$ & $125.235,00$ & $\mathrm{Rp}$ & $1.127 .115,00$ \\
\hline 18 & Pas. Kabel power NYY 4 × $10 \mathrm{~mm}^{2}$ LVMDP - PAB & - & $\mathrm{m}^{\prime}$ & 45,00 & $\mathrm{Rp}$ & $52.200,00$ & Rp & $2.349 .000,00$ \\
\hline 19 & Pas. Kabel Tray $300 \times 100 \mathrm{~mm}$ & - & $\mathrm{m}^{\prime}$ & 86,00 & $\mathrm{Rp}$ & $338.000,00$ & $\mathrm{Rp}$ & $29.068 .000,00$ \\
\hline 20 & Pas. Arde & - & Ls & 1,00 & $\mathrm{Rp}$ & $2.854 .000,00$ & $\mathrm{Rp}$ & $2.854 .000,00$ \\
\hline & & - & & & & & & \\
\hline 21 & $\begin{array}{l}\text { Air Terminal type electrostatic ( Prevectron 3) radius } 100 \\
\text { meter }\end{array}$ & - & bh & 1,00 & $\mathrm{Rp}$ & $7.757 .000,00$ & $\mathrm{Rp}$ & $7.757 .000,00$ \\
\hline 22 & $\begin{array}{l}\text { Grounding (Electroda \& plat tembaga, resistensi max } 2 \\
\text { ohm) }\end{array}$ & - & ls & 1,00 & $\mathrm{Rp}$ & $3.927 .000,00$ & $\mathrm{Rp}$ & $3.927 .000,00$ \\
\hline & Include box control & - & & & & & & \\
\hline 24 & Tesl Link & - & ls & 1,00 & $\mathrm{Rp}$ & $232.300,00$ & $\mathrm{Rp}$ & $232.300,00$ \\
\hline 25 & Construction Obstruction Lamp & - & bh & 1,00 & $\mathrm{Rp}$ & $3.385 .000,00$ & $\mathrm{Rp}$ & $3.385 .000,00$ \\
\hline 26 & NYY $1 \times 70 \mathrm{~mm} 2$ & - & $\mathrm{m}^{\prime}$ & 80,00 & $\mathrm{Rp}$ & $297.800,00$ & $\mathrm{Rp}$ & $23.824 .000,00$ \\
\hline 27 & Tiang penyangga & - & bh & 1,00 & $\mathrm{Rp}$ & $2.219 .000,00$ & $\mathrm{Rp}$ & $2.219 .000,00$ \\
\hline 28 & Support Material & - & ls & 1,00 & $\mathrm{Rp}$ & $1.668 .000,00$ & $\mathrm{Rp}$ & $1.668 .000,00$ \\
\hline 29 & Perijinan & - & ls & 1,00 & $\mathrm{Rp}$ & $4.423 .000,00$ & $\mathrm{Rp}$ & $4.423 .000,00$ \\
\hline \multicolumn{7}{|c|}{ SUB TOTAL III - A } & $\mathbf{R p}$ & 297.742.274,64 \\
\hline $\mathbf{B}$ & SANITASI - LANTAI 1 & & & & & & & \\
\hline 1 & Pas. Pipa Galvanis 3/4" & $7 . \mathrm{a}$ & $\mathrm{m}^{\prime}$ & 120,00 & $\mathrm{Rp}$ & $39.489,57$ & $\mathrm{Rp}$ & $4.738 .748,00$ \\
\hline 2 & Pas. Pipa Galvanis 1" & $7 . \mathrm{b}$ & $\mathrm{m}^{\prime}$ & 33,00 & $\mathrm{Rp}$ & $44.531,23$ & $\mathrm{Rp}$ & $1.469 .530,70$ \\
\hline 3 & Pas. Pipa Galvanis $11 / 2^{\prime \prime}$ & $7 . \mathrm{c}$ & $\mathrm{m}^{\prime}$ & 42,00 & $\mathrm{Rp}$ & $71.084,35$ & $\mathrm{Rp}$ & $2.985 .542,84$ \\
\hline 4 & Pas. Gate Valve 1" & - & bh & 1,00 & $\mathrm{Rp}$ & $1.976,92$ & $\mathrm{Rp}$ & $1.976,92$ \\
\hline 5 & Pas. Gate Valve $11 / 2 "$ & - & bh & 2,00 & $\mathrm{Rp}$ & $99.245,00$ & $\mathrm{Rp}$ & $198.490,00$ \\
\hline 6 & Pas. Pompa submersible 1 ltr/dtk H-50m berikut perlengk & - & bh & 1,00 & $\mathrm{Rp}$ & $99.245,00$ & $\mathrm{Rp}$ & $99.245,00$ \\
\hline 7 & Pas. Pipa PVC dia. 1 (Venting) & $7 . \mathrm{d}$ & $\mathrm{m}^{\prime}$ & 92,00 & $\mathrm{Rp}$ & $36.525,34$ & $\mathrm{Rp}$ & $3.360 .331,28$ \\
\hline 8 & Pas. Pipa PVC dia. 1 1/2" (Mandi/Cuci) & 7.e & $\mathrm{m}^{\prime}$ & 12,00 & $\mathrm{Rp}$ & $50.475,34$ & $\mathrm{Rp}$ & $605.704,08$ \\
\hline 9 & Pas. Pipa PVC dia. 3" (Mandi/Cuci) & $7 . \mathrm{f}$ & $\mathrm{m}^{\prime}$ & 12,00 & $\mathrm{Rp}$ & $118.808,63$ & $\mathrm{Rp}$ & $1.425 .703,56$ \\
\hline 10 & Pas. Pipa PVC dia. 4" (Mandi/Cuci) & $7 . g$ & $\mathrm{~m}^{\prime}$ & 84,00 & $\mathrm{Rp}$ & $160.658,63$ & $\mathrm{Rp}$ & $13.495 .324,92$ \\
\hline 11 & Pas. Pipa PVC dia. 4" (Air Kotor) & $7 . g$ & $\mathrm{~m}^{\prime}$ & 84,00 & $\mathrm{Rp}$ & $160.658,63$ & $\mathrm{Rp}$ & $13.495 .324,92$ \\
\hline 12 & Pas. Clean Out dia. 4" (Air Kotor) & - & bh & 2,00 & $\mathrm{Rp}$ & $423.000,00$ & $\mathrm{Rp}$ & $846.000,00$ \\
\hline 13 & Pas. Clean Out dia. 3" (Mandi/Cuci) & - & bh & 2,00 & $\mathrm{Rp}$ & $381.000,00$ & $\mathrm{Rp}$ & $762.000,00$ \\
\hline 14 & Pas. Septictank kap. $3 \mathrm{~m}^{3}$ & - & bh & 2,00 & $\mathrm{Rp}$ & $945.000,00$ & $\mathrm{Rp}$ & $1.890 .000,00$ \\
\hline 15 & Pek. Bak Kontrol & - & $\mathrm{Bh}$ & 2,00 & $\mathrm{Rp}$ & $758.000,00$ & $\mathrm{Rp}$ & $1.890 .000,00$ \\
\hline 16 & Pas.Urinoir & $7 . \mathrm{j}$ & $\mathrm{Bh}$ & 3,00 & $\mathrm{Rp}$ & $1.356 .822,52$ & $\mathrm{Rp}$ & $4.070 .467,57$ \\
\hline 17 & Pas. Westafel & $7 . \mathrm{i}$ & $\mathrm{Bh}$ & 7,00 & $\mathrm{Rp}$ & $1.051 .626,36$ & $\mathrm{Rp}$ & $7.361 .384,55$ \\
\hline 18 & Pas. Toilet duduk & $7 . \mathrm{h}$ & $\mathrm{Bh}$ & 8,00 & $\mathrm{Rp}$ & $2.950 .743,96$ & $\mathrm{Rp}$ & $23.605 .951,68$ \\
\hline \multicolumn{7}{|c|}{ SUB TOTAL III - B } & Rp & $82.301 .726,03$ \\
\hline
\end{tabular}


JURNAL KACAPURI

JURNAL KEILMUAN TEKNIK SIPIL

Volume 4 Nomor 2 Edisi Desember 2021

\begin{tabular}{|c|c|c|c|c|c|c|c|c|}
\hline \multirow[t]{2}{*}{$\mathrm{C}$} & \multicolumn{8}{|l|}{ PEKERJAAN DATA } \\
\hline & PERALATAN UTAMA & & & & & & & \\
\hline 1 & Server & - & $\mathrm{Bh}$ & 1,00 & $\mathrm{Rp}$ & $28.304 .000,00$ & $\mathrm{Rp}$ & $28.304 .000,00$ \\
\hline 2 & \begin{tabular}{|l|} 
Personal Computer \\
\end{tabular} & - & $\mathrm{Bh}$ & 1,00 & $\mathrm{Rp}$ & $10.684 .000,00$ & $\mathrm{Rp}$ & $10.684 .000,00$ \\
\hline 3 & Printer & - & $\mathrm{Bh}$ & 1,00 & $\mathrm{Rp}$ & $5.186 .000,00$ & $\mathrm{Rp}$ & $5.186 .000,00$ \\
\hline 4 & Router & - & $\mathrm{Bh}$ & 1,00 & $R p$ & $3.821 .000,00$ & $\mathrm{Rp}$ & $3.821 .000,00$ \\
\hline 5 & Main Switch Hub 48 port & - & $\mathrm{Bh}$ & 1,00 & $\mathrm{Rp}$ & $15.978 .000,00$ & $\mathrm{Rp}$ & $15.978 .000,00$ \\
\hline 6 & Switch Hub 24 port & - & $\mathrm{Bh}$ & 2,00 & $R p$ & $7.677 .000,00$ & Rp & $15.354 .000,00$ \\
\hline 7 & Arrester & - & $\mathrm{Bh}$ & 1,00 & $R p$ & $1.774 .000,00$ & $\mathrm{Rp}$ & $1.774 .000,00$ \\
\hline 8 & UPS 2 KVA & - & $\mathrm{Bh}$ & 1,00 & $R p$ & $13.661 .000,00$ & $\mathrm{Rp}$ & $13.661 .000,00$ \\
\hline 9 & Wire Management & - & Ls & 1,00 & $R p$ & $6.824 .000,00$ & $\mathrm{Rp}$ & $6.824 .000,00$ \\
\hline 10 & Standing Rack & - & Unit & 1,00 & $R p$ & $11.829 .000,00$ & $R p$ & $11.829 .000,00$ \\
\hline 11 & Setting Peralatan Utama + Testing Commissioning & - & Lot & 1,00 & $\mathrm{Rp}$ & $13.328 .000,00$ & $\mathrm{Rp}$ & $13.328 .000,00$ \\
\hline & & & & & & & & \\
\hline & LANTAI - 1 & & & & & & & \\
\hline 1 & Wall Mount Rack & - & unit & 1,00 & $\mathrm{Rp}$ & $10.646 .000,00$ & $\mathrm{Rp}$ & $10.646 .000,00$ \\
\hline 2 & \begin{tabular}{|l} 
Switch Hub 24 Port \\
\end{tabular} & - & unit & 1,00 & $R p$ & $6.449 .000,00$ & $\mathrm{Rp}$ & $6.449 .000,00$ \\
\hline 3 & Patch Panel 24 Port & - & unit & 1,00 & $R p$ & $5.596 .000,00$ & $\mathrm{Rp}$ & $5.596 .000,00$ \\
\hline 4 & Data Outlet & - & bh & 13,00 & $R p$ & $282.000,00$ & $\mathrm{Rp}$ & $3.666 .000,00$ \\
\hline 5 & Instalasi Kabel LAN & - & ttk & 13,00 & $R p$ & $633.000,00$ & Rp & $8.229 .000,00$ \\
\hline & & & & & & & & \\
\hline & LANTAI - 2 & & & & & & & \\
\hline 1 & Wall Mount Rack & - & unit & 1,00 & $\mathrm{Rp}$ & $10.646 .000,00$ & $\mathrm{Rp}$ & $10.646 .000,00$ \\
\hline 2 & \begin{tabular}{|l|} 
Switch Hub 24 Port \\
\end{tabular} & - & unit & 1,00 & $R p$ & $6.449 .000,00$ & $\mathrm{Rp}$ & $6.449 .000,00$ \\
\hline 3 & Patch Panel 24 Port & - & unit & 1,00 & $R p$ & $5.596 .000,00$ & $\mathrm{Rp}$ & $5.596 .000,00$ \\
\hline 4 & Data Outlet & - & $\mathrm{bh}$ & 13,00 & $R p$ & $282.000,00$ & $\mathrm{Rp}$ & $3.666 .000,00$ \\
\hline 5 & $\begin{array}{l}\text { Instalasi Kabel LAN } \\
\end{array}$ & - & $\mathrm{ttk}$ & 13,00 & $R p$ & $633.000,00$ & $\mathrm{Rp}$ & $8.229 .000,00$ \\
\hline & & & & & & JB TOTAL IV - C & $\mathbf{R p}$ & $195.915 .000,00$ \\
\hline & & & & & & & & \\
\hline D & PEKERJAAN MATV & & & & & & & \\
\hline & Peralatan Utama & & & & & & & \\
\hline 1 & Antena UHV & - & unit & 1,00 & $\mathrm{Rp}$ & $2.723 .000,00$ & $\mathrm{Rp}$ & $2.723 .000,00$ \\
\hline 2 & Antena VHF & - & unit & 1,00 & $\mathrm{Rp}$ & $1.956 .000,00$ & $\mathrm{Rp}$ & $1.956 .000,00$ \\
\hline 3 & Divider & - & unit & 1,00 & $\mathrm{Rp}$ & $971.000,00$ & $R p$ & $971.000,00$ \\
\hline 4 & Modulator & - & unit & 1,00 & Rp & $4.811 .000,00$ & $R p$ & $4.811 .000,00$ \\
\hline 5 & Main Spliter & - & unit & 1,00 & $\mathrm{Rp}$ & $971.000,00$ & $\mathrm{Rp}$ & $971.000,00$ \\
\hline 6 & Main Boster & - & unit & 1,00 & $\mathrm{Rp}$ & $7.882 .000,00$ & $\mathrm{Rp}$ & $7.882 .000,00$ \\
\hline 7 & Head end CATV & - & unit & 1,00 & $\mathrm{Rp}$ & $8.176 .000,00$ & $\mathrm{Rp}$ & $8.176 .000,00$ \\
\hline 8 & Spliter 2 way & - & unit & 1,00 & $\mathrm{Rp}$ & $1.253 .000,00$ & $\mathrm{Rp}$ & $1.253 .000,00$ \\
\hline 9 & Spliter 4 way & - & unit & 2,00 & $\mathrm{Rp}$ & $1.355 .000,00$ & $\mathrm{Rp}$ & $2.710 .000,00$ \\
\hline 10 & Active combiner & - & unit & 1,00 & $R p$ & $5.578 .000,00$ & $\mathrm{Rp}$ & $5.578 .000,00$ \\
\hline & \begin{tabular}{|l|} 
INSTALASI MATV \\
\end{tabular} & & & & $\mathrm{Rp}$ & - & & \\
\hline & LANTAI - 1 & & & & Rp & - & & \\
\hline 1 & Stop Kontak power & - & bh & 1,00 & $\mathrm{Rp}$ & $50.000,00$ & $\mathrm{Rp}$ & $50.000,00$ \\
\hline 2 & Boster $48 \mathrm{db}$ & - & bh & 1,00 & $\mathrm{Rp}$ & $3.494 .000,00$ & $\mathrm{Rp}$ & $3.494 .000,00$ \\
\hline 3 & Outlet TV & - & bh & 1,00 & $\mathrm{Rp}$ & $109.000,00$ & $\mathrm{Rp}$ & $109.000,00$ \\
\hline 4 & Tap off 2 way & - & bh & 1,00 & Rp & $597.000,00$ & $R p$ & $597.000,00$ \\
\hline 5 & Tap off 4 way & - & bh & 1,00 & $R p$ & $832.000,00$ & $\mathrm{Rp}$ & $832.000,00$ \\
\hline 6 & Instalasi (kabel RG 6+counduit ega) & - & ttk & 1,00 & $\mathrm{Rp}$ & $706.000,00$ & $\mathrm{Rp}$ & $706.000,00$ \\
\hline & LANTAI - 2 & & & & $\mathrm{Rp}$ & - & & \\
\hline 1 & Stop Kontak power & - & bh & 1,00 & $\mathrm{Rp}$ & $50.000,00$ & $\mathrm{Rp}$ & $50.000,00$ \\
\hline 2 & Boster $48 \mathrm{db}$ & - & bh & 1,00 & Rp & $3.494 .000,00$ & $\mathrm{Rp}$ & $3.494 .000,00$ \\
\hline 3 & Outlet TV & - & bh & 1,00 & $\mathrm{Rp}$ & $109.000,00$ & $\mathrm{Rp}$ & $109.000,00$ \\
\hline 4 & Tap off 2 way & - & bh & 1,00 & Rp & $597.000,00$ & Rp & $597.000,00$ \\
\hline 5 & Tap off 4 way & - & bh & 1,00 & Rp & $832.000,00$ & $\mathrm{Rp}$ & $832.000,00$ \\
\hline 6 & Instalasi (kabel RG 6+counduit ega) & - & $\mathrm{ttk}$ & 1,00 & $\mathrm{Rp}$ & $706.000,00$ & $\mathrm{Rp}$ & $706.000,00$ \\
\hline & & & & & & B TOTAL IV - D & $\mathbf{R p}$ & $48.607 .000,00$ \\
\hline & & & & & & & & \\
\hline & & & & & & & & \\
\hline $\mathbf{E}$ & PEKERJAAN SOUND SISTEM & & & & & & & \\
\hline & Lantai - 1 & & & & & & & \\
\hline & RUANG AULA & & & & & & & \\
\hline 1 & Amplifier 240 watt & - & bh & 1,00 & $\mathrm{Rp}$ & $3.899 .000,00$ & $\mathrm{Rp}$ & $3.899 .000,00$ \\
\hline 2 & Mixer & - & bh & 1,00 & Rp & $10.526 .000,00$ & $\mathrm{Rp}$ & $10.526 .000,00$ \\
\hline 3 & Radio tuner, dvd player, deck \& mic public address & - & bh & 1,00 & $\mathrm{Rp}$ & $13.332 .000,00$ & $\mathrm{Rp}$ & $13.332 .000,00$ \\
\hline 4 & Microphone desk & - & bh & 1,00 & Rp & $1.287 .000,00$ & Rp & $1.287 .000,00$ \\
\hline 5 & Speaker Switch Selection 10 zone & - & bh & 1,00 & $\mathrm{Rp}$ & $3.767 .000,00$ & $\mathrm{Rp}$ & $3.767 .000,00$ \\
\hline 6 & MDF - SS & - & bh & 1,00 & $\mathrm{Rp}$ & $791.000,00$ & $\mathrm{Rp}$ & $791.000,00$ \\
\hline 7 & Rack Sound sistem $19 \mathrm{RU}$ & - & bh & 1,00 & $\mathrm{Rp}$ & $9.180 .000,00$ & $\mathrm{Rp}$ & $9.180 .000,00$ \\
\hline 8 & Kolom Speaker & - & bh & 6,00 & Rp & $3.662 .000,00$ & $\mathrm{Rp}$ & $21.972 .000,00$ \\
\hline 9 & Instalasi sound sistem & - & ttk & 6,00 & $\mathrm{Rp}$ & $685.000,00$ & $\mathrm{Rp}$ & $4.110 .000,00$ \\
\hline 10 & Wiring sistem peralatan utama & - & is & 1,00 & $\mathrm{Rp}$ & $1.569 .000,00$ & $\mathrm{Rp}$ & $1.569 .000,00$ \\
\hline & RUANG UMUM & & & & & & & \\
\hline 1 & Amplifier 240 watt & - & bh & 1,00 & $\mathrm{Rp}$ & $3.899 .000,00$ & $\mathrm{Rp}$ & $3.899 .000,00$ \\
\hline 2 & Mixer & - & bh & 1,00 & Rp & $10.526 .000,00$ & $\mathrm{Rp}$ & $10.526 .000,00$ \\
\hline 3 & Radio tuner, dvd player, deck \& mic public address & - & bh & 1,00 & Rp & $13.332 .000,00$ & $\mathrm{Rp}$ & $13.332 .000,00$ \\
\hline 4 & Microphone desk & - & bh & 1,00 & $\mathrm{Rp}$ & $1.287 .000,00$ & $\mathrm{Rp}$ & $1.287 .000,00$ \\
\hline 5 & Speaker Switch Selection 10 zone & - & bh & 1,00 & $\mathrm{Rp}$ & $3.767 .000,00$ & $\mathrm{Rp}$ & $3.767 .000,00$ \\
\hline 6 & MDF - SS & - & bh & 1,00 & Rp & $784.000,00$ & $\mathrm{Rp}$ & $784.000,00$ \\
\hline 7 & Rack Sound sistem 19 RU & - & bh & 1,00 & $\mathrm{Rp}$ & $9.180 .000,00$ & $\mathrm{Rp}$ & $9.180 .000,00$ \\
\hline 8 & TB - SS & - & bh & 1,00 & $\mathrm{Rp}$ & $591.000,00$ & $\mathrm{Rp}$ & $591.000,00$ \\
\hline 9 & Celling Speaker, 3 watt & - & bh & 30,00 & $\mathrm{Rp}$ & $205.000,00$ & $\mathrm{Rp}$ & $6.150 .000,00$ \\
\hline 10 & Volume kontrol & - & bh & 16,00 & $R p$ & $369.000,00$ & $\mathrm{Rp}$ & $5.904 .000,00$ \\
\hline 11 & Instalasi sound sistem & - & ttk & 30,00 & $\mathrm{Rp}$ & $685.000,00$ & $\mathrm{Rp}$ & $20.550 .000,00$ \\
\hline 12 & Wiring sistem peralatan utama & - & 1s & 1,00 & $\mathrm{Rp}$ & $1.569 .000,00$ & $\mathrm{Rp}$ & $1.569 .000,00$ \\
\hline
\end{tabular}


JURNAL KACAPURI

JURNAL KEILMUAN TEKNIK SIPIL Volume 4 Nomor 2 Edisi Desember 2021

\begin{tabular}{|c|c|c|c|c|c|c|c|c|}
\hline & Lantai - 2 & & & & & & & \\
\hline & RUANG SIDANG & & & & & & & \\
\hline 1 & Amplifier 240 watt & - & bh & 2,00 & $\mathrm{Rp}$ & $3.899 .000,00$ & $\mathrm{Rp}$ & $7.798 .000,00$ \\
\hline 2 & Radio tuner, dvd player, deck \& mic public address & - & bh & 2,00 & $\mathrm{Rp}$ & $13.332 .000,00$ & $\mathrm{Rp}$ & $26.664 .000,00$ \\
\hline 3 & Microphone desk & - & bh & 2,00 & $\mathrm{Rp}$ & $1.279 .000,00$ & $\mathrm{Rp}$ & $2.558 .000,00$ \\
\hline 4 & MDF - SS & - & bh & 2,00 & $\mathrm{Rp}$ & $2.692 .000,00$ & $\mathrm{Rp}$ & $5.384 .000,00$ \\
\hline 5 & Rack Sound sistem $19 \mathrm{RU}$ & - & bh & 2,00 & $\mathrm{Rp}$ & $9.180 .000,00$ & $\mathrm{Rp}$ & $18.360 .000,00$ \\
\hline 6 & Kolom Speaker & - & bh & 4,00 & $\mathrm{Rp}$ & $3.662 .000,00$ & $\mathrm{Rp}$ & $14.648 .000,00$ \\
\hline 7 & Celling Speaker, 3 watt & - & bh & 4,00 & $\mathrm{Rp}$ & $204.000,00$ & $\mathrm{Rp}$ & $816.000,00$ \\
\hline 8 & Instalasi sound sistem & - & ttk & 8,00 & $\mathrm{Rp}$ & $400.000,00$ & $\mathrm{Rp}$ & $3.200 .000,00$ \\
\hline \multirow[t]{2}{*}{9} & Wiring sistem peralatan utama & - & ls & 2,00 & $\mathrm{Rp}$ & $1.569 .000,00$ & $\mathrm{Rp}$ & $3.138 .000,00$ \\
\hline & RUANG UMUM & & & & & & & \\
\hline 1 & Amplifier 240 watt & - & $\mathrm{bh}$ & 1,00 & $\mathrm{Rp}$ & $3.899 .000,00$ & $\mathrm{Rp}$ & $3.899 .000,00$ \\
\hline 2 & Mixer & - & $\mathrm{bh}$ & 1,00 & $\mathrm{Rp}$ & $10.526 .000,00$ & $\mathrm{Rp}$ & $10.526 .000,00$ \\
\hline 3 & Radio tuner, dvd player, deck \& mic public address & - & bh & 1,00 & $\mathrm{Rp}$ & $13.332 .000,00$ & $\mathrm{Rp}$ & $13.332 .000,00$ \\
\hline 4 & Microphone desk & - & bh & 1,00 & $\mathrm{Rp}$ & $1.279 .000,00$ & $\mathrm{Rp}$ & $1.279 .000,00$ \\
\hline 5 & Speaker Switch Selection 10 zone & - & bh & 1,00 & $\mathrm{Rp}$ & $784.000,00$ & $\mathrm{Rp}$ & $784.000,00$ \\
\hline 6 & MDF - SS & - & bh & 1,00 & $\mathrm{Rp}$ & $2.692 .000,00$ & $\mathrm{Rp}$ & $2.692 .000,00$ \\
\hline 7 & Rack Sound sistem $19 \mathrm{RU}$ & - & bh & 1,00 & $\mathrm{Rp}$ & $9.180 .000,00$ & $\mathrm{Rp}$ & $9.180 .000,00$ \\
\hline 8 & TB - SS & - & bh & 1,00 & $\mathrm{Rp}$ & $591.000,00$ & $\mathrm{Rp}$ & $591.000,00$ \\
\hline 9 & Celling Speaker, 3 watt & - & bh & 27,00 & $\mathrm{Rp}$ & $204.000,00$ & $\mathrm{Rp}$ & $5.508 .000,00$ \\
\hline 10 & Volume kontrol & - & bh & 17,00 & $\mathrm{Rp}$ & $369.000,00$ & $\mathrm{Rp}$ & $6.273 .000,00$ \\
\hline 11 & Instalasi sound sistem & - & ttk & 27,00 & $\mathrm{Rp}$ & $400.000,00$ & $\mathrm{Rp}$ & $10.800 .000,00$ \\
\hline \multirow[t]{2}{*}{12} & Wiring sistem peralatan utama & - & 1s & 1,00 & $\mathrm{Rp}$ & $1.569 .000,00$ & $\mathrm{Rp}$ & $1.569 .000,00$ \\
\hline & \multicolumn{6}{|c|}{ SUB TOTAL IV - E } & $\mathbf{R p}$ & $296.971 .000,00$ \\
\hline \multirow[t]{2}{*}{$\mathbf{F}$} & PEKERJAAN TELEPHONE & & & & & & & \\
\hline & Lantai - 1 & & & & & & & \\
\hline 1 & PABX Telephone 12/120 & - & bh & 1,00 & $\mathrm{Rp}$ & $54.861 .000,00$ & $\mathrm{Rp}$ & $54.861 .000,00$ \\
\hline 2 & MDF-TP 100 Pairs & - & bh & 1,00 & $\mathrm{Rp}$ & $1.569 .000,00$ & Rp & $1.569 .000,00$ \\
\hline 3 & Personal Computer & - & bh & 1,00 & $\mathrm{Rp}$ & $6.802 .000,00$ & Rp & $6.802 .000,00$ \\
\hline 4 & Printer & - & bh & 1,00 & \begin{tabular}{|l|l|}
$\mathrm{Rp}$ \\
\end{tabular} & $1.569 .000,00$ & Rp & $1.569 .000,00$ \\
\hline 5 & Power Surge Arrester & - & bh & 1,00 & $\mathrm{Rp}$ & $4.066 .000,00$ & Rp & $4.066 .000,00$ \\
\hline 6 & Battery dan Charger & - & bh & 1,00 & $\mathrm{Rp}$ & $5.051 .000,00$ & $\mathrm{Rp}$ & $5.051 .000,00$ \\
\hline 7 & Operator Console & - & bh & 1,00 & $\mathrm{Rp}$ & $2.500 .000,00$ & $\mathrm{Rp}$ & $2.500 .000,00$ \\
\hline 8 & Wiring sistem dan pemrograman & - & 1s & 1,00 & $\mathrm{Rp}$ & $3.139 .000,00$ & $\mathrm{Rp}$ & $3.139 .000,00$ \\
\hline 9 & Terminal box telephon & - & bh & 1,00 & $\mathrm{Rp}$ & $680.000,00$ & $\mathrm{Rp}$ & $680.000,00$ \\
\hline 10 & Shocket outlet telephon & - & bh & 17,00 & $\mathrm{Rp}$ & $88.000,00$ & $\mathrm{Rp}$ & $1.496 .000,00$ \\
\hline \multirow[t]{3}{*}{11} & Instalasi telephon & - & ttk & 17,00 & $\mathrm{Rp}$ & $631.000,00$ & $\mathrm{Rp}$ & $10.727 .000,00$ \\
\hline & & - & & & & & & \\
\hline & Lantai - 2 & - & & & & & & \\
\hline 1 & Terminal box telephon & - & bh & 1,00 & $\mathrm{Rp}$ & $680.000,00$ & $\mathrm{Rp}$ & $680.000,00$ \\
\hline 2 & Shocket outlet telephon & - & bh & 15,00 & $\mathrm{Rp}$ & $88.000,00$ & $\mathrm{Rp}$ & $1.320 .000,00$ \\
\hline \multirow[t]{2}{*}{3} & Instalasi telephon & - & ttk & 15,00 & $\mathrm{Rp}$ & $627.000,00$ & $\mathrm{Rp}$ & $9.405 .000,00$ \\
\hline & & & & & & & Rp & $103.865 .000,00$ \\
\hline $\mathbf{G}$ & PEKERJAAN PENANGKAL PETIR DAN GROUNDING & & & & & & & \\
\hline 1 & Splitter electrostatis radius 150 meter & - & bh & 1,00 & $\mathrm{Rp}$ & $19.560 .000,00$ & $\mathrm{Rp}$ & $19.560 .000,00$ \\
\hline 2 & Kabel BC $50 \mathrm{~mm}$ & - & $\mathrm{m}$ & 80,00 & $\mathrm{Rp}$ & $146.000,00$ & $\mathrm{Rp}$ & $11.680 .000,00$ \\
\hline 3 & $\begin{array}{l}\text { Grounding (Electroda \& plat tembaga, resistensi max } 2 \\
\text { ohm) Include box control }\end{array}$ & - & ls & 1,00 & $\mathrm{Rp}$ & $4.107 .000,00$ & $\mathrm{Rp}$ & $3.900 .000,00$ \\
\hline \multirow[t]{3}{*}{4} & Support Material dan aksesoris & - & ls & 1,00 & $\mathrm{Rp}$ & $635.000,00$ & $\mathrm{Rp}$ & $635.000,00$ \\
\hline & & & & & & B TOTAL IV - G & $\mathbf{R p}$ & $35.775 .000,00$ \\
\hline & & & & SUB TOTAL V & $-(A+)$ & $B+C+D+E+F+G)$ & $\mathbf{R p}$ & $1.094 .241 .000,00$ \\
\hline
\end{tabular}

Sumber: Hasil Analisis 
JURNAL KACAPURI

JURNAL KEILMUAN TEKNIK SIPIL Volume 4 Nomor 2 Edisi Desember 2021

Rekapitulasi Rencana Anggaran Biaya Metode Analisa Harga Satuan Pekerjaan (AHSP) Bidang Cipta Karya Peraturan Menteri PUPR Nomor 28 Tahun 2016 dapat dilihat pada tabel dibawah ini.

Tabel 7. Rekapitulasi Rencana Anggaran Biaya metode AHSP Bidang Cipta Karya Peraturan Menteri PUPR Nomor 28 Tahun 2016

\begin{tabular}{|c|c|c|c|c|c|c|c|c|}
\hline NO & URAIAN PEKERJAAN & Analisis & SAT & VOLUME & \multicolumn{2}{|c|}{$\begin{array}{c}\text { HARGA } \\
\text { SATUAN( Rp. ) }\end{array}$} & \multicolumn{2}{|c|}{ JUMLAH HARGA ( Rp. ) } \\
\hline $\mathrm{a}$ & $\mathrm{b}$ & & c & $\mathrm{d}$ & & $\mathrm{e}$ & & $\mathrm{f}$ \\
\hline I & PEK. STRUKTUR RANGKA ATAP & & & & & & & \\
\hline $\mathbf{A}$ & PEK. ATAP BAJA & & & & & & & \\
\hline 1 & Pek. Baja IWF 350x350x12x19mm & $6 . \mathrm{a}$ & $\mathrm{Kg}$ & 17894,34 & $\mathrm{Rp}$ & $70.585,1$ & $\mathrm{Rp}$ & $1.263 .073 .545,8$ \\
\hline 2 & Pek. Baja IWF 200x100x5.5x8 mm & $6 . a$ & $\mathrm{Kg}$ & 1711,17 & $\mathrm{Rp}$ & $70.585,1$ & $\mathrm{Rp}$ & $120.782 .791,7$ \\
\hline 3 & Pek. Baja IWF 250x125x6x9 mm & $6 . a$ & $\mathrm{Kg}$ & 1319,73 & $\mathrm{Rp}$ & $70.585,1$ & $\mathrm{Rp}$ & $93.153 .014,4$ \\
\hline 4 & Pek. Baja IWF 300x150x6.5x9 mm & $6 . a$ & $\mathrm{Kg}$ & 2256,30 & $\mathrm{Rp}$ & $70.585,1$ & $\mathrm{Rp}$ & $159.261 .156,0$ \\
\hline 5 & Pek. Baja IWF 350x175x7x11 mm & $6 . \mathrm{a}$ & $\mathrm{Kg}$ & 18771,82 & $\mathrm{Rp}$ & $70.585,1$ & $\mathrm{Rp}$ & $1.325 .010 .760,9$ \\
\hline 6 & Pek. Baja IWF 400x200x8x13 mm & $6 . \mathrm{a}$ & $\mathrm{Kg}$ & 2058,02 & $\mathrm{Rp}$ & $70.585,1$ & $\mathrm{Rp}$ & $145.265 .225,5$ \\
\hline 7 & Pek. Baja C 125.50.20.2,3 & 6.b & $\mathrm{Kg}$ & 7036,34 & $\mathrm{Rp}$ & $31.985,7$ & $\mathrm{Rp}$ & $225.061 .890,1$ \\
\hline 8 & Pek. Base Plate & - & $\mathrm{Kg}$ & 991,23 & $\mathrm{Rp}$ & $27.705,0$ & $\mathrm{Rp}$ & $27.461 .892,8$ \\
\hline 9 & Pek. Pasang mur - baut & - & bh & 2184,09 & $\mathrm{Rp}$ & $10.500,0$ & $\mathrm{Rp}$ & $22.932 .933,0$ \\
\hline 10 & Pek. Pasang ikatan angin & - & $\mathrm{Kg}$ & 509,52 & $\mathrm{Rp}$ & $15.612,0$ & $\mathrm{Rp}$ & $7.954 .658,8$ \\
\hline 11 & Pek. Pasang angkur & - & bh & 295,95 & $\mathrm{Rp}$ & $62.000,0$ & $\mathrm{Rp}$ & $18.348 .714,0$ \\
\hline \multirow[t]{2}{*}{12} & Pek. Pasang jarum keras & - & bh & 44,39 & $\mathrm{Rp}$ & $33.000,0$ & $\mathrm{Rp}$ & $1.464 .937,7$ \\
\hline & & & & & \multicolumn{2}{|c|}{ SUB TOTAL A } & $\mathbf{R p}$ & 3.409.771.520,8 \\
\hline II & PEK. STRUKTUR BETON & & & & & & & \\
\hline \multirow[t]{2}{*}{$\mathbf{A}$} & LANTAI 1 & & & & & & & \\
\hline & \multicolumn{3}{|c|}{ PEKERJAAN BETON, BEKISTING \& PEM BESIAN } & & & & & \\
\hline 1 & Pek. Beton Kolom 15/15 & $1 . \mathrm{a}$ & $\mathrm{m} 3$ & 6,03 & & $1.123 .757,56$ & & $6.776 .258,11$ \\
\hline 2 & Pek. Bekisting Kolom & 1.b & $\mathrm{m} 2$ & 0,27 & & $356.350,03$ & & $96.927,21$ \\
\hline \multirow[t]{2}{*}{3} & Pek. Pembesian Kolom & 1.c & $\mathrm{Kg}$ & 3,56 & & $20.376,87$ & & $72.451,11$ \\
\hline & & & & & \multicolumn{2}{|c|}{ SUB TOTAL II - A } & & 6.945.636,42 \\
\hline \multirow[t]{2}{*}{ B } & LANTAI 2 & & & & & & & \\
\hline & \multicolumn{3}{|c|}{ PEKERJAAN BETON, BEKISTING \& PEM BESIAN } & & & & & \\
\hline 1 & Pek. Beton Kolom 15/15 & 1.a & $\mathrm{m} 3$ & 6,48 & $\mathrm{Rp}$ & $1.123 .757,56$ & $\mathrm{Rp}$ & $7.281 .949,01$ \\
\hline 2 & Pek. Bekisting Kolom & $1 . \mathrm{b}$ & $\mathrm{m} 2$ & 0,27 & $\mathrm{Rp}$ & $356.350,03$ & $\mathrm{Rp}$ & $96.927,21$ \\
\hline \multirow[t]{3}{*}{3} & Pek. Pembesian Kolom & $1 . \mathrm{c}$ & $\mathrm{Kg}$ & 3,56 & \multirow{2}{*}{\multicolumn{2}{|c|}{$\begin{array}{lr}\mathrm{Rp} \quad 20.376,87 \\
\text { SUB TOTAL II - B } \\
\end{array}$}} & $\mathrm{Rp}$ & $72.451,11$ \\
\hline & & & & & & & $\mathbf{R p}$ & $7.451 .327,32$ \\
\hline & & & & & \multicolumn{2}{|c|}{ UB TOTAL II - $(A+B)$} & $\mathbf{R p}$ & $14.396 .963,74$ \\
\hline
\end{tabular}

Sumber: Hasil Analisis

Daftar Rencana Anggaran Biaya menggunakan Metode Analisa Harga Satuan Pekerjaan (AHSP) Bidang Cipta Karya Peraturan Menteri PUPR Nomor 28 Tahun 2016, terbagi menjadi 4 (empat) bidang pekerjaan, dapat dilihat pada tabel dibawah ini. 
JURNAL KACAPURI

JURNAL KEILMUAN TEKNIK SIPIL Volume 4 Nomor 2 Edisi Desember 2021

Tabel 8. Daftar Rencana Anggaran Biaya Metode AHSP Bidang Cipta Karya Peraturan Menteri PUPR Nomor 28 Tahun 2016 Bidang Pekerjaan Arsitektur

\begin{tabular}{|c|c|c|c|c|c|c|c|c|}
\hline \multirow{3}{*}{$\begin{array}{l}\text { NO } \\
\mathrm{a} \\
\end{array}$} & \multirow{2}{*}{$\begin{array}{c}\text { URAIAN PEKERJAAN } \\
\mathrm{b}\end{array}$} & & \multirow{2}{*}{$\begin{array}{c}\text { SAT } \\
\mathrm{c} \\
\end{array}$} & \multirow{2}{*}{\begin{tabular}{|c|} 
VOLUME \\
$\mathrm{d}$ \\
\end{tabular}} & \multicolumn{2}{|c|}{$\begin{array}{c}\text { HARGA SATUAN( } \\
\text { Rp.) }\end{array}$} & \multicolumn{2}{|c|}{ JUM LAH HARGA ( Rp. ) } \\
\hline & & & & & & $\mathrm{e}$ & & $\mathrm{f}$ \\
\hline & PEKERJAAN ARSITEKTUR LANTAI 1 & & & & & & & \\
\hline I & PEKERJAAN PERSIAPAN & & & & & & & \\
\hline \multirow[t]{2}{*}{1} & Alat Bantu & - & Ls & 1,00 & $\mathrm{Rp}$ & $4.500 .000,00$ & $\mathrm{Rp}$ & $4.500 .000,00$ \\
\hline & & & & & & SUB TOTAL I & $\mathbf{R p}$ & $4.500 .000,00$ \\
\hline II & PEKERJAAN PASANGAN DINDING + PLESTERAN + ACIAN & & & & & & & \\
\hline 1 & Memasang dinding bata merah & 2.a & $\mathrm{m} 2$ & 2803,64 & $\mathrm{Rp}$ & $149.903,45$ & $\mathrm{Rp}$ & $420.275 .314,84$ \\
\hline 2 & Membuat plesteran semen Pc & 2.b & $\mathrm{m} 2$ & 5607,28 & $\mathrm{Rp}$ & $68.244,47$ & $\mathrm{Rp}$ & $382.665 .827,97$ \\
\hline 3 & Membuat acian semen Pc & 2.c & $\mathrm{m} 2$ & 5607,28 & $\mathrm{Rp}$ & $41.169,99$ & $\mathrm{Rp}$ & $230.851 .661,53$ \\
\hline 4 & Membuat plesteran kolom-balok semen Pc & $2 . \mathrm{b}$ & $\mathrm{m} 2$ & 570,00 & $\mathrm{Rp}$ & $68.244,47$ & $\mathrm{Rp}$ & $38.899 .345,48$ \\
\hline 5 & Membuat acian kolom-balok semen Pc & 2.c & $\mathrm{m} 2$ & 570,00 & $\mathrm{Rp}$ & $41.169,99$ & $\mathrm{Rp}$ & $23.466 .894,30$ \\
\hline \multirow[t]{2}{*}{6} & Membuat pasangan benangan & - & $\mathrm{m}$ & 370,00 & $\mathrm{Rp}$ & $35.000,00$ & $\mathrm{Rp}$ & $12.950 .000,00$ \\
\hline & & & & & & SUB TOTAL II & $\mathbf{R p}$ & $1.109 .109 .044,12$ \\
\hline III & PEKERJAAN LANTAI \& DINDING KERAM IK & & & & & & & \\
\hline 1 & Pek. Urugan Pasir Bawah Lantai & 3.a & $\mathrm{m} 3$ & 125,80 & $\mathrm{Rp}$ & $243.860,49$ & $\mathrm{Rp}$ & $30.677 .649,39$ \\
\hline 2 & Pek. Lantai Homogeunes Tile 60/60 & 3.c & $\mathrm{m} 2$ & 991,28 & $\mathrm{Rp}$ & $465.693,36$ & $\mathrm{Rp}$ & $461.632 .516,50$ \\
\hline 3 & Pek. Keramik 30/30 (KM/WC) & 3.b & $\mathrm{m} 2$ & 53,62 & $\mathrm{Rp}$ & $275.273,97$ & $\mathrm{Rp}$ & $14.760 .190,36$ \\
\hline \multirow[t]{2}{*}{4} & Pek. Lantai Tangga Keramik 30/30 & 3.b & $\mathrm{m} 2$ & 41,38 & $\mathrm{Rp}$ & $275.273,97$ & $\mathrm{Rp}$ & $11.389 .460,57$ \\
\hline & & & & & & SUB TOTAL III & $\mathbf{R p}$ & $518.459 .816,82$ \\
\hline IV & PEKERJAAN PINTU DAN JENDELA & & & & & & & \\
\hline 1 & Kusen \& Pintu Type P1 & - & Unit & 2,00 & $\mathrm{Rp}$ & $2.500 .000,00$ & $\mathrm{Rp}$ & $5.000 .000,00$ \\
\hline 1 & Kusen \& Pintu Type P2 & - & Unit & 4,00 & $\mathrm{Rp}$ & $1.500 .000,00$ & $\mathrm{Rp}$ & $6.000 .000,00$ \\
\hline 2 & Kusen \& Pintu Type P3 & - & Unit & 1,00 & $\mathrm{Rp}$ & $1.500 .000,00$ & $\mathrm{Rp}$ & $1.500 .000,00$ \\
\hline 3 & Kusen \& Pintu Type P4 & - & Unit & 16,00 & $\mathrm{Rp}$ & $1.000 .000,00$ & $\mathrm{Rp}$ & $16.000 .000,00$ \\
\hline 4 & Kusen \& Pintu Type P5 & - & Unit & 2,00 & $\mathrm{Rp}$ & $700.000,00$ & $\mathrm{Rp}$ & $1.400 .000,00$ \\
\hline 5 & Kusen \& Pintu Type P6 & - & Unit & 2,00 & $\mathrm{Rp}$ & $700.000,00$ & $\mathrm{Rp}$ & $1.400 .000,00$ \\
\hline 6 & Kusen \& Pintu Type P7 & - & Unit & 10,00 & $\mathrm{Rp}$ & $700.000,00$ & $\mathrm{Rp}$ & $7.000 .000,00$ \\
\hline 7 & Kusen \& Jendela J1 & - & Unit & 32,00 & $\mathrm{Rp}$ & $1.250 .000,00$ & $\mathrm{Rp}$ & $40.000 .000,00$ \\
\hline 8 & Kusen \& Jendela J2 & - & Unit & 4,00 & $\mathrm{Rp}$ & $3.600 .000,00$ & $\mathrm{Rp}$ & $14.400 .000,00$ \\
\hline \multirow[t]{2}{*}{9} & Ventilasi & - & Unit & 12,00 & $\mathrm{Rp}$ & $250.000,00$ & $\mathrm{Rp}$ & $3.000 .000,00$ \\
\hline & & & & & & SUB TOTAL IV & $\mathbf{R p}$ & $95.700 .000,00$ \\
\hline $\mathbf{v}$ & PEKERJAAN PLAFOND & & & & & & & \\
\hline 1 & Pek. Plafond Gypsum + Rangka Hollow & 4.a & $\mathrm{m} 2$ & 991,28 & $\mathrm{Rp}$ & $275.580,32$ & $\mathrm{Rp}$ & $273.177 .255,64$ \\
\hline 2 & Pek. Plafond Kalsiboard + Rangka Hollow & 4.b & $\mathrm{m} 2$ & 53,62 & $\mathrm{Rp}$ & $227.869,18$ & $\mathrm{Rp}$ & $12.218 .345,43$ \\
\hline \multirow[t]{2}{*}{3} & Pek. List plafond Gypsum & 4.c & m’ & 1567,35 & $\mathrm{Rp}$ & $24.666,58$ & $\mathrm{Rp}$ & $38.661 .156,33$ \\
\hline & & & & & & SUB TOTAL V & $\mathbf{R p}$ & $324.056 .757,40$ \\
\hline VI & PEKERJAAN PENGECATAN & & & & & & & \\
\hline 1 & Pek. Cat Tembok Ekterior (Weathershield) & 5.a & $\mathrm{m} 2$ & 521,64 & $\mathrm{Rp}$ & $52.613,04$ & $\mathrm{Rp}$ & $27.445 .066,19$ \\
\hline 2 & Pek. Cat Tembok Interior (Emulsion) & 5.b & $\mathrm{m} 2$ & 5083,64 & $\mathrm{Rp}$ & $46.139,56$ & $\mathrm{Rp}$ & $234.556 .912,80$ \\
\hline 3 & Pek. Cat Plafond Gypsum & 5.b & $\mathrm{m} 2$ & 991,28 & $\mathrm{Rp}$ & $46.139,56$ & $\mathrm{Rp}$ & $45.737 .223,04$ \\
\hline \multirow[t]{2}{*}{4} & Pek. Cat List Plafond & $5 . c$ & $\mathrm{~m}$ & 1567,35 & $\mathrm{Rp}$ & $53.276,81$ & $\mathrm{Rp}$ & $83.503 .400,32$ \\
\hline & & & & & & SUB TOTAL VI & $\mathbf{R p}$ & $391.242 .602,34$ \\
\hline VII & PEKERJAAN SECONDARY SKIN, ACCESSORY & & & & & & & \\
\hline \multirow[t]{2}{*}{1} & Pek. Railing Tangga & - & $\mathrm{m}^{\prime}$ & 20,00 & $\mathrm{Rp}$ & $815.000,00$ & $\mathrm{Rp}$ & $16.300 .000,00$ \\
\hline & & & & & & SUB TOTAL VII & $\mathbf{R p}$ & $16.300 .000,00$ \\
\hline & & & & & UB TC & TTAL LANTAI 1 & $\mathbf{R p}$ & 2.459.368.220,68 \\
\hline & PEKERJAAN ARSITEKTUR LANTAI 2 & & & & & & & \\
\hline I & PEKERJAAN PASANGAN DINDING + PLESTERAN + ACIAN & & & & & & & \\
\hline 1 & Memasang dinding bata merah & 2.a & $\mathrm{m} 2$ & 3001,40 & $\mathrm{Rp}$ & $149.903,45$ & $\mathrm{Rp}$ & $449.920 .221,55$ \\
\hline 2 & Membuat plesteran semen Pc & $2 . b$ & $\mathrm{~m} 2$ & 6002,80 & $\mathrm{Rp}$ & $68.244,47$ & $\mathrm{Rp}$ & $409.657 .879,06$ \\
\hline 3 & Membuat acian semen Pc & $2 . \mathrm{c}$ & $\mathrm{m} 2$ & 6002,80 & $\mathrm{Rp}$ & $41.169,99$ & $\mathrm{Rp}$ & $247.135 .215,97$ \\
\hline 4 & Membuat plesteran kolom-balok semen Pc & $2 . \mathrm{b}$ & $\mathrm{m} 2$ & 939,00 & $\mathrm{Rp}$ & $68.244,47$ & $\mathrm{Rp}$ & $64.081 .553,35$ \\
\hline 5 & Membuat acian kolom-balok semen Pc & 2.c & $\mathrm{m} 2$ & 939,00 & $\mathrm{Rp}$ & $41.169,99$ & $\mathrm{Rp}$ & $38.658 .620,61$ \\
\hline 6 & Membuat pasangan benangan & - & $\mathrm{m} 1$ & 370,00 & $\mathrm{Rp}$ & $35.000,00$ & $\mathrm{Rp}$ & $12.950 .000,00$ \\
\hline & & & & & & SUB TOTAL I & $\mathbf{R p}$ & $1.222 .403 .490,55$ \\
\hline II & PEKERJAAN LANTAI \& DINDING KERAM IK & & & & & & & \\
\hline 1 & Pek. Urugan Pasir Bawah Lantai & 3.a & $\mathrm{m} 3$ & 130,80 & $\mathrm{Rp}$ & $243.860,49$ & $\mathrm{Rp}$ & $31.896 .951,83$ \\
\hline 2 & Pek. Lantai Homogeunes Tile $60 / 60$ & 3.c & $\mathrm{m} 2$ & 910,00 & $\mathrm{Rp}$ & $465.693,36$ & $\mathrm{Rp}$ & $423.780 .959,98$ \\
\hline 3 & Pek. Keramik 30/30 (KM/WC) & 3.b & $\mathrm{m} 2$ & 58,32 & $\mathrm{Rp}$ & $275.273,97$ & $\mathrm{Rp}$ & $16.053 .978,02$ \\
\hline & & & & 968,32 & & SUB TOTAL II & $\mathbf{R p}$ & $471.731 .889,84$ \\
\hline
\end{tabular}


JURNAL KACAPURI

JURNAL KEILMUAN TEKNIK SIPIL

Volume 4 Nomor 2 Edisi Desember 2021

\begin{tabular}{|c|c|c|c|c|c|c|c|}
\hline III & PEKERJAAN PINTU DAN JENDELA & & & & & & \\
\hline 2 & Kusen \& Pintu Type P2 & - & Unit & 4,00 & $\mathrm{Rp} \quad 1.500 .000,00$ & $\mathrm{Rp}$ & $6.000 .000,00$ \\
\hline 3 & Kusen \& Pintu Type P3 & - & Unit & 1,00 & $\mathrm{Rp} \quad 1.500 .000,00$ & $\mathrm{Rp}$ & $1.500 .000,00$ \\
\hline 4 & Kusen \& Pintu Type P4 & - & Unit & 16,00 & $\mathrm{Rp} \quad 1.000 .000,00$ & $\mathrm{Rp}$ & $16.000 .000,00$ \\
\hline 5 & Kusen \& Pintu Type P5 & - & Unit & 2,00 & $700.000,00$ & $\mathrm{Rp}$ & $1.400 .000,00$ \\
\hline 6 & Kusen \& Pintu Type P6 & - & Unit & 2,00 & $700.000,00$ & $\mathrm{Rp}$ & $1.400 .000,00$ \\
\hline 7 & Kusen \& Pintu Type P7 & - & Unit & 10,00 & $700.000,00$ & $\mathrm{Rp}$ & $7.000 .000,00$ \\
\hline 8 & Kusen \& Jendela J1 & - & Unit & 32,00 & $\mathrm{Rp} \quad 1.250 .000,00$ & $\mathrm{Rp}$ & $40.000 .000,00$ \\
\hline 9 & Kusen \& Jendela J2 & - & Unit & 4,00 & $\mathrm{Rp} \quad 3.600 .000,00$ & $\mathrm{Rp}$ & $14.400 .000,00$ \\
\hline \multirow[t]{2}{*}{10} & Ventilasi & - & Unit & 12,00 & $250.000,00$ & $\mathrm{Rp}$ & $3.000 .000,00$ \\
\hline & & & & & SUB TOTAL III & $\mathbf{R p}$ & $90.700 .000,00$ \\
\hline IV & PEKERJAAN PLAFOND & & & & & & \\
\hline 1 & Pek. Plafond Gypsum+ Rangka Hollow & 4.a & $\mathrm{m} 2$ & 1175,20 & $275.580,32$ & $\mathrm{Rp}$ & $323.861 .987,36$ \\
\hline 2 & Pek. Plafond Kalsiboard + Rangka Hollow & 4.b & $\mathrm{m} 2$ & 58,32 & $227.869,18$ & $\mathrm{Rp}$ & 13.289.330,58 \\
\hline \multirow[t]{2}{*}{3} & Pek. List plafond Gypsum & $4 . c$ & $\mathrm{~m}^{\prime}$ & 1663,98 & $24.666,58$ & $\mathrm{Rp}$ & $41.044 .687,47$ \\
\hline & & & & & SUB TOTAL IV & $\mathbf{R p}$ & $378.196 .005,41$ \\
\hline $\mathbf{v}$ & PEKERJAAN PENGECATAN & & & & & & \\
\hline 1 & Pek. Cat Tembok Ekterior (Weathershield) & 5.a & $\mathrm{m} 2$ & 496,80 & $52.613,04$ & $\mathrm{Rp}$ & $26.138 .158,27$ \\
\hline 2 & Pek. Cat Tembok Interior (Emulsion) & 5.b & $\mathrm{m} 2$ & 5506,00 & $46.139,56$ & $\mathrm{Rp}$ & $254.044 .417,36$ \\
\hline 3 & Pek. Cat Plafond & 5.b & $\mathrm{m} 2$ & 1109,32 & $46.139,56$ & $\mathrm{Rp}$ & $51.183 .536,70$ \\
\hline \multirow[t]{2}{*}{4} & Pek. Cat List Plafond & 5.c & $\mathrm{m}$ & 1663,98 & $53.276,81$ & $\mathrm{Rp}$ & $88.651 .537,98$ \\
\hline & & & & & SUB TOTAL $\mathrm{V}$ & $\mathbf{R p}$ & $420.017 .650,32$ \\
\hline VI & PEKERJAAN ATAP & & & & & & \\
\hline 1 & Pasang Lapisan kedap air & 6.c & $\mathrm{m} 2$ & 1676,54 & $248.745,35$ & $\mathrm{Rp}$ & $417.031 .470,72$ \\
\hline 2 & Pasang Rangka Primer & $6 . d$ & $\mathrm{~kg}$ & 3936 & $25.888,77$ & $\mathrm{Rp}$ & $101.898 .093,72$ \\
\hline 3 & Pasang Rangka Sekunder Panel & $6 . \mathrm{e}$ & $\mathrm{kg}$ & 9982,19 & $26.636,22$ & $\mathrm{Rp}$ & $265.887 .873,16$ \\
\hline 4 & Pasang Plat Tumpuan Panel & $6 . \mathrm{f}$ & Pcs & 12417 & $10.649,75$ & $\mathrm{Rp}$ & $132.237 .595,22$ \\
\hline 5 & Pasang Plat Tumpuan Sekunder $\&$ Braket & $6 . \mathrm{g}$ & Pcs & 9312 & $23.389,75$ & $\mathrm{Rp}$ & $217.805 .328,72$ \\
\hline 5 & Pasang Pedestal & $6 . \mathrm{h}$ & Pcs & 533,5 & $85.491,16$ & $\mathrm{Rp}$ & $45.609 .531,19$ \\
\hline \multirow[t]{2}{*}{6} & Pasang Penutup Atap Ornamental & $6 . \mathrm{i}$ & $\mathrm{m} 2$ & 1867,25 & $\mathrm{Rp} \quad 1.354 .599,95$ & $\mathrm{Rp}$ & 2.529.376.756,64 \\
\hline & & & & & SUB TOTAL VI & $\mathbf{R p}$ & $3.709 .846 .649,37$ \\
\hline \multicolumn{6}{|r|}{ SUB TOTAL LANTAI 2} & $\mathbf{R p}$ & $6.292 .895 .685,48$ \\
\hline \multicolumn{6}{|c|}{ JUMLAH TOTAL PEKERJAAN ARSITEKTUR } & $\mathbf{R p}$ & $8.752 .263 .906,15$ \\
\hline
\end{tabular}

Sumber: Hasil Analisis

Tabel 9. Daftar Rencana Anggaran Biaya Metode AHSP Bidang Cipta Karya Peraturan Menteri PUPR Nomor 28 Tahun 2016 Bidang Pekerjaan Interior dan ACP

Sumber: RAB Kontraktor

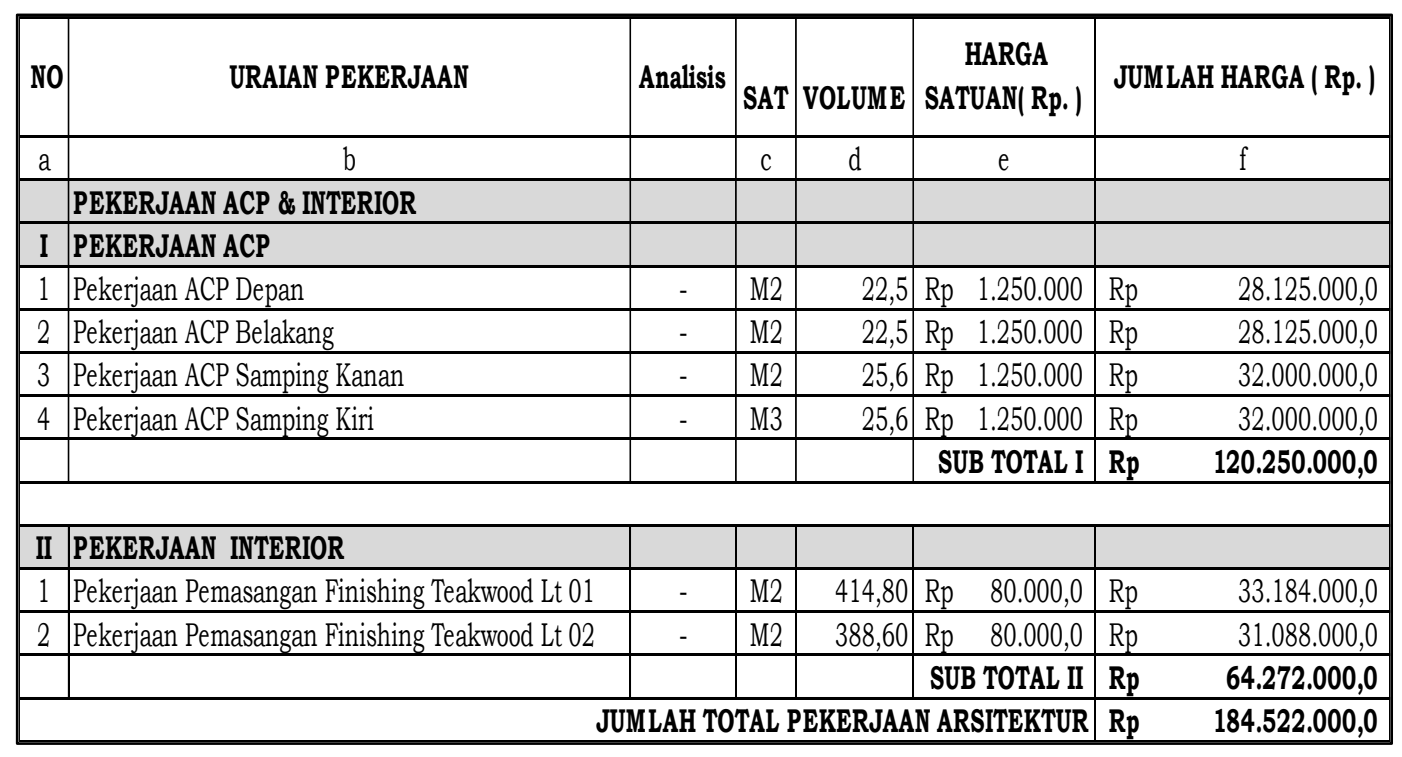


JURNAL KACAPURI

JURNAL KEILMUAN TEKNIK SIPIL Volume 4 Nomor 2 Edisi Desember 2021

Tabel 10. Daftar Rencana Anggaran Biaya Metode AHSP Bidang Cipta Karya Peraturan Menteri PUPR Nomor 28 Tahun 2016 Bidang Pekerjaan Mekanikal, Elektrikal, Plumbing dan

$\mathrm{AC}$

\begin{tabular}{|c|c|c|c|c|c|c|c|}
\hline No & URAIAN PEKERJAAN & $\begin{array}{c}\text { No. } \\
\text { Analisis }\end{array}$ & SAT & VOLUME & $\begin{array}{l}\text { HARGA SATUAN( } \\
\text { Rp. ) }\end{array}$ & \multicolumn{2}{|c|}{ JUMLAH HARGA ( Rp. ) } \\
\hline $\mathrm{a}$ & $\mathrm{b}$ & & c & $\mathrm{d}$ & $\mathrm{e}$ & \multicolumn{2}{|r|}{$\mathrm{f}$} \\
\hline & & & & & & & \\
\hline \multirow[t]{6}{*}{ I } & PEKERJAAN PENYAM BUNGAN DAYA LISTRIK & & & & & & \\
\hline & & & & & & & \\
\hline & Pasang Baru Daya Listrik 131.000VA & & & & & & \\
\hline & BP \& UJL & - & $\mathrm{VA}$ & $131.000,00$ & 630,00 & $\mathrm{Rp}$ & $82.530 .000,00$ \\
\hline & Biaya pengurusan, Sertifikasi ( SLO ) \& Energized & - & $\mathrm{VA}$ & $131.000,00$ & 100,00 & $\mathrm{Rp}$ & $13.100 .000,00$ \\
\hline & & & & & & & \\
\hline \multicolumn{6}{|r|}{ SUB TOTAL I } & $\mathbf{R p}$ & $95.630 .000,00$ \\
\hline \multirow[t]{2}{*}{ II } & PEKERJAAN TATA UDARA & & & & & & \\
\hline & Peralatan Utama & & & & & & \\
\hline $\mathbf{A}$ & Lantai - 1 & & & & & & \\
\hline & Sistem - 1 & & & & & & \\
\hline 1 & Indoor unit Wall Mounted kap. $12.300 \mathrm{Btu} / \mathrm{h}$ & - & unit & 1,00 & \begin{tabular}{|ll} 
Rp & $14.800 .000,00$ \\
\end{tabular} & $\mathrm{Rp}$ & $14.800 .000,00$ \\
\hline 2 & Indoor unit Wall Mounted kap. $15.400 \mathrm{Btu} / \mathrm{h}$ & - & unit & 1,00 & Rp $15.804 .000,00$ & $\mathrm{Rp}$ & $15.804 .000,00$ \\
\hline 3 & Indoor unit Wall Mounted kap. $19.100 \mathrm{Btu} / \mathrm{h}$ & - & unit & 1,00 & Rp $\quad 18.417 .000,00$ & $\mathrm{Rp}$ & $18.417 .000,00$ \\
\hline 4 & Indoor unit Split duct kap. $54.600 \mathrm{Btu} / \mathrm{h}$ & - & unit & 1,00 & $\mathrm{Rp} \quad 31.506 .000,00$ & $\mathrm{Rp}$ & $31.506 .000,00$ \\
\hline 5 & Indoor unit Split duct kap. $76.400 \mathrm{Btu} / \mathrm{h}$ & - & unit & 1,00 & \begin{tabular}{|ll}
$\mathrm{Rp}$ & $52.700 .000,00$ \\
\end{tabular} & $\mathrm{Rp}$ & $52.700 .000,00$ \\
\hline 6 & Out door unit kap. $191.000 \mathrm{Btu} / \mathrm{h}$ & - & unit & 1,00 & Rp 203.643.000,00 & $\mathrm{Rp}$ & $203.643 .000,00$ \\
\hline & Sistem - 2 & & & & & & \\
\hline 7 & Indoor unit Wall Mounted kap. $9.600 \mathrm{Btu} / \mathrm{h}$ & - & unit & 1,00 & $\begin{array}{ll}\mathrm{Rp} & 14.125 .000,00 \\
\end{array}$ & $\mathrm{Rp}$ & $14.125 .000,00$ \\
\hline 8 & Indoor unit Wall Mounted kap. $12.300 \mathrm{Btu} / \mathrm{h}$ & - & unit & 1,00 & $\begin{array}{ll}\mathrm{Rp} & 14.620 .000,00 \\
\end{array}$ & $\mathrm{Rp}$ & $14.620 .000,00$ \\
\hline 9 & Indoor unit Wall Mounted kap. $19.100 \mathrm{Btu} / \mathrm{h}$ & - & unit & 1,00 & $\begin{array}{ll}\mathrm{Rp} & 18.248 .000,00 \\
\end{array}$ & $\mathrm{Rp}$ & $18.248 .000,00$ \\
\hline 10 & Indoor unit Split duct kap. $76.400 \mathrm{Btu} / \mathrm{h}$ & - & unit & 1,00 & $\begin{array}{ll}\mathrm{Rp} & 52.754 .000,00 \\
\end{array}$ & $\mathrm{Rp}$ & $52.754 .000,00$ \\
\hline 11 & Out door unit kap. $171.000 \mathrm{Btu} / \mathrm{h}$ & - & unit & 1,00 & Rp $183.252 .000,00$ & $\mathrm{Rp}$ & $183.252 .000,00$ \\
\hline 12 & Indoor + Outdoor unit Wall Mounted kap. $9.000 \mathrm{Btu} / \mathrm{h}$ & - & unit & 2,00 & \begin{tabular}{|ll}
$\mathrm{Rp}$ & $5.107 .000,00$ \\
\end{tabular} & $\mathrm{Rp}$ & $10.214 .000,00$ \\
\hline 13 & Indoor + Outdoor unit Wall Mounted kap. $11.400 \mathrm{Btu} / \mathrm{h}$ & - & unit & 2,00 & $6.230 .000,00$ & $\mathrm{Rp}$ & $12.460 .000,00$ \\
\hline & & & & & SUB TOTAL II - A & $\mathbf{R p}$ & $642.543 .000,00$ \\
\hline B & Lantai - 2 & & & & & & \\
\hline & Sistem - 1 & & & & & & \\
\hline 1 & Indoor unit Wall Mounted kap. $12.300 \mathrm{Btu} / \mathrm{h}$ & - & unit & 2,00 & \begin{tabular}{|ll}
$\mathrm{Rp}$ & $14.620 .000,00$ \\
\end{tabular} & $\mathrm{Rp}$ & $29.240 .000,00$ \\
\hline 2 & Indoor unit Wall Mounted kap. $15.400 \mathrm{Btu} / \mathrm{h}$ & - & unit & 1,00 & Rp $15.804 .000,00$ & $\mathrm{Rp}$ & $15.804 .000,00$ \\
\hline 3 & Indoor unit Wall Mounted kap. $19.100 \mathrm{Btu} / \mathrm{h}$ & - & unit & 2,00 & Rp $\quad 18.248 .000,00$ & $\mathrm{Rp}$ & $36.496 .000,00$ \\
\hline 4 & Indoor unit Wall Mounted kap. $24.200 \mathrm{Btu} / \mathrm{h}$ & - & unit & 1,00 & $\begin{array}{ll}\mathrm{Rp} & 19.551 .000,00 \\
\end{array}$ & $\mathrm{Rp}$ & $19.551 .000,00$ \\
\hline 5 & Indoor unit Split duct kap. $47.800 \mathrm{Btu} / \mathrm{h}$ & - & unit & 1,00 & Rp $28.750 .000,00$ & $\mathrm{Rp}$ & $28.750 .000,00$ \\
\hline 6 & Indoor unit Split duct kap. $95.500 \mathrm{Btu} / \mathrm{h}$ & - & unit & 1,00 & $\begin{array}{ll}\mathrm{Rp} & 58.775 .000,00 \\
\end{array}$ & $\mathrm{Rp}$ & $58.775 .000,00$ \\
\hline 7 & Out door unit kap. $290.000 \mathrm{Btu} / \mathrm{h}$ & - & unit & 1,00 & Rp $290.584 .000,00$ & $\mathrm{Rp}$ & $290.584 .000,00$ \\
\hline & Sistem - 2 & & & & & & \\
\hline 1 & Indoor unit Wall Mounted kap. $12.300 \mathrm{Btu} / \mathrm{h}$ & - & unit & 2,00 & \begin{tabular}{|ll} 
Rp & $14.620 .000,00$ \\
\end{tabular} & $\mathrm{Rp}$ & $29.240 .000,00$ \\
\hline 2 & Indoor unit Wall Mounted kap. $15.400 \mathrm{Btu} / \mathrm{h}$ & - & unit & 2,00 & Rp $15.804 .000,00$ & $\mathrm{Rp}$ & $31.608 .000,00$ \\
\hline 3 & Indoor unit Wall Mounted kap. $19.100 \mathrm{Btu} / \mathrm{h}$ & - & unit & 2,00 & \begin{tabular}{|ll}
$\mathrm{Rp}$ & $18.248 .000,00$ \\
\end{tabular} & $\mathrm{Rp}$ & $36.496 .000,00$ \\
\hline 4 & Indoor unit Wall Mounted kap. $24.200 \mathrm{Btu} / \mathrm{h}$ & - & unit & 1,00 & \begin{tabular}{|ll}
$\mathrm{Rp}$ & $19.551 .000,00$ \\
\end{tabular} & $\mathrm{Rp}$ & $19.551 .000,00$ \\
\hline 5 & Indoor unit Split duct kap. $38.200 \mathrm{Btu} / \mathrm{h}$ & - & unit & 1,00 & \begin{tabular}{|ll}
$\mathrm{Rp}$ & $26.979 .000,00$ \\
\end{tabular} & Rp & $26.979 .000,00$ \\
\hline 6 & Out door unit kap. $273.000 \mathrm{Btu} / \mathrm{h}$ & - & unit & 1,00 & Rp $279.675 .000,00$ & $\mathrm{Rp}$ & $279.675 .000,00$ \\
\hline & & & & & SUB TOTAL II - B & $\mathbf{R p}$ & 902.749.000,00 \\
\hline & INSTALASI TATA UDARA & & & & & & \\
\hline $\mathbf{C}$ & Lantai - 1 & & & & & & \\
\hline 1 & Instalasi pipa refrigerant lengkap isolasi $\varnothing 7 / 8 "+15 / 8^{\prime \prime}$ & - & $\mathrm{m}^{1}$ & 172,00 & $526.000,00$ & $\mathrm{Rp}$ & $90.472 .000,00$ \\
\hline 2 & Instalasi pipa refrigerant lengkap isolasi $\varnothing 1 / 4 "+1 / 2^{\prime \prime}$ & - & $\mathrm{m}^{1}$ & 64,00 & $213.000,00$ & $\mathrm{Rp}$ & $13.632 .000,00$ \\
\hline 3 & Instalasi pipa refrigerant lengkap isolasi $\varnothing 1 / 4^{\prime \prime}+5 / 8^{\prime \prime}$ & - & $\mathrm{m}^{1}$ & 43,00 & $231.000,00$ & $\mathrm{Rp}$ & $9.933 .000,00$ \\
\hline 4 & Instalasi pipa refrigerant lengkap isolasi Ø $3 / 8^{\prime \prime}+3 / 4^{\prime \prime}$ & - & $\mathrm{m}^{1}$ & 51,00 & $260.000,00$ & $\mathrm{Rp}$ & $13.260 .000,00$ \\
\hline 5 & Instalasi pipa refrigerant lengkap isolasi $\varnothing 3 / 8 "+5 / 8^{\prime \prime}$ & - & $\mathrm{m}^{1}$ & 37,00 & $245.000,00$ & $\mathrm{Rp}$ & $9.065 .000,00$ \\
\hline 6 & Instalasi pipa refrigerant lengkap isolasi $\varnothing 3 / 8^{\prime \prime}+3 / 4^{\prime \prime}$ & - & $\mathrm{m}^{1}$ & 33,00 & $260.000,00$ & $\mathrm{Rp}$ & $8.580 .000,00$ \\
\hline 7 & Instalasi pipa refrigerant lengkap isolasi $\varnothing 5 / 8+11 / 8^{\prime \prime}$ & - & $\mathrm{m}^{1}$ & 23,00 & $357.000,00$ & $\mathrm{Rp}$ & $8.211 .000,00$ \\
\hline 8 & Refnet joint & - & bh & 15,00 & $2.834 .000,00$ & $\mathrm{Rp}$ & $42.510 .000,00$ \\
\hline 9 & Instalasi kabel power dan kabel kontrol indoor & - & ttk & 30,00 & $1.486 .000,00$ & $\mathrm{Rp}$ & $44.580 .000,00$ \\
\hline 10 & Instalasi kabel power outdoor & - & ttk & 2,00 & $7.331 .000,00$ & $\mathrm{Rp}$ & $14.662 .000,00$ \\
\hline 11 & Instalasi pipa drain lengkap isolasi & - & ttk & 30,00 & $506.000,00$ & $\mathrm{Rp}$ & $15.180 .000,00$ \\
\hline 12 & $\begin{array}{l}\text { Instalasi ducting supply bahan BJLS, Glass wool, } \\
\text { Allumunium foil : }\end{array}$ & - & & & & & \\
\hline & ducting supply BJLS 50 & - & $\mathrm{m}^{2}$ & 158,00 & $469.000,00$ & $\mathrm{Rp}$ & $74.102 .000,00$ \\
\hline & ducting supply BJLS 60 & - & $\mathrm{m}^{2}$ & 77,00 & $541.000,00$ & $\mathrm{Rp}$ & $41.657 .000,00$ \\
\hline & ducting return BJLS 50 & - & $\mathrm{m}^{2}$ & 132,00 & $465.000,00$ & $\mathrm{Rp}$ & $61.380 .000,00$ \\
\hline & ducting return BJLS 60 & - & $\mathrm{m}^{2}$ & 58,00 & $543.000,00$ & $\mathrm{Rp}$ & $31.494 .000,00$ \\
\hline 13 & Flexible duct Ø 250 & - & $\mathrm{m}^{1}$ & 64,00 & $348.000,00$ & $\mathrm{Rp}$ & $22.272 .000,00$ \\
\hline 14 & Pan drain & - & bh & 3,00 & $1.177 .000,00$ & $\mathrm{Rp}$ & $3.531 .000,00$ \\
\hline 15 & Plenum supply dan return & - & bh & 6,00 & $3.901 .000,00$ & $\mathrm{Rp}$ & $23.406 .000,00$ \\
\hline 16 & Supply Air Diffuser 250 x 250 & - & bh & 22,00 & $422.000,00$ & $\mathrm{Rp}$ & $9.284 .000,00$ \\
\hline 17 & Return Air Grille 200 x 600 & - & bh & 12,00 & $568.000,00$ & $\mathrm{Rp}$ & $6.816 .000,00$ \\
\hline 18 & Pengisian freon R410 & - & lot & 1,00 & $\begin{array}{ll}\mathrm{Rp} & 11.596 .000,00 \\
\end{array}$ & $\mathrm{Rp}$ & $11.596 .000,00$ \\
\hline 19 & Panel outdoor AC & - & unit & 1,00 & $\begin{array}{ll}\mathrm{Rp} & 18.700 .000,00 \\
\end{array}$ & $\mathrm{Rp}$ & $18.700 .000,00$ \\
\hline 20 & Pas. Kabel power NYY 4 × $10 \mathrm{~mm}^{2}$ & - & $\mathrm{m}^{\prime}$ & 200,00 & $113.000,00$ & $\mathrm{Rp}$ & $22.600 .000,00$ \\
\hline & & & & & SUB TOTAL II - C & $\mathbf{R p}$ & $596.923 .000,00$ \\
\hline
\end{tabular}


JURNAL KACAPURI

JURNAL KEILMUAN TEKNIK SIPIL

Volume 4 Nomor 2 Edisi Desember 2021

\begin{tabular}{|c|c|c|c|c|c|c|c|c|}
\hline D & Lantai - 2 & & & & & & & \\
\hline 1 & Instalasi pipa refrigerant lengkap isolasi Ø $7 / 8^{\prime \prime}+13 / 8^{\prime \prime}$ & - & $\mathrm{m}^{1}$ & 144,00 & $\mathrm{Rp}$ & $526.000,00$ & $\mathrm{Rp}$ & $75.744 .000,00$ \\
\hline 2 & Instalasi pipa refrigerant lengkap isolasi $\varnothing 1 / 4^{\prime \prime}+1 / 2^{\prime \prime}$ & - & $\mathrm{m}^{1}$ & 72,00 & $\mathrm{Rp}$ & $213.000,00$ & $\mathrm{Rp}$ & $15.336 .000,00$ \\
\hline 3 & Instalasi pipa refrigerant lengkap isolasi $\varnothing 1 / 4^{\prime \prime}+5 / 8^{\prime \prime}$ & - & $\mathrm{m}^{1}$ & 67,00 & $\mathrm{Rp}$ & $231.000,00$ & $\mathrm{Rp}$ & $15.477 .000,00$ \\
\hline 4 & Instalasi pipa refrigerant lengkap isolasi Ø $3 / 8^{\prime \prime}+3 / 4^{\prime \prime}$ & - & $\mathrm{m}^{1}$ & 44,00 & $\mathrm{Rp}$ & $260.000,00$ & $\mathrm{Rp}$ & $11.440 .000,00$ \\
\hline 5 & Instalasi pipa refrigerant lengkap isolasi Ø $5 / 8 "+11 / 8$ & - & $\mathrm{m}^{1}$ & 27,00 & $\mathrm{Rp}$ & $357.000,00$ & $\mathrm{Rp}$ & $9.639 .000,00$ \\
\hline 6 & Refnet joint & - & bh & 15,00 & $\mathrm{Rp}$ & $3.270 .000,00$ & $\mathrm{Rp}$ & $49.050 .000,00$ \\
\hline 7 & Instalasi kabel power dan kabel kontrol indoor & - & ttk & 22,00 & $\mathrm{Rp}$ & $1.783 .000,00$ & $\mathrm{Rp}$ & $39.226 .000,00$ \\
\hline 8 & Instalasi kabel power outdoor & - & ttk & 2,00 & $\mathrm{Rp}$ & $10.181 .000,00$ & $\mathrm{Rp}$ & $20.362 .000,00$ \\
\hline 9 & Instalasi pipa drain lengkap isolasi & - & ttk & 22,00 & $\mathrm{Rp}$ & $506.000,00$ & $\mathrm{Rp}$ & $11.132 .000,00$ \\
\hline \multirow[t]{5}{*}{10} & $\begin{array}{l}\text { Instalasi ducting supply bahan BJLS, Glass wool, } \\
\text { Allumunium foil : }\end{array}$ & - & & & & & & \\
\hline & ducting supply BJLS 50 & - & $\mathrm{m}^{2}$ & 253,00 & $\mathrm{Rp}$ & $469.000,00$ & $\mathrm{Rp}$ & $118.657 .000,00$ \\
\hline & ducting supply BJLS 60 & - & $\mathrm{m}^{2}$ & 94,00 & $\mathrm{Rp}$ & $541.000,00$ & $\mathrm{Rp}$ & $50.854 .000,00$ \\
\hline & ducting return BJLS 50 & - & $\mathrm{m}^{2}$ & 188,00 & $\mathrm{Rp}$ & $465.000,00$ & $\mathrm{Rp}$ & $87.420 .000,00$ \\
\hline & ducting return BJLS 60 & - & $\mathrm{m}^{2}$ & 76,00 & $\mathrm{Rp}$ & $543.000,00$ & $\mathrm{Rp}$ & $41.268 .000,00$ \\
\hline 13 & Flexible duct Ø 250 & - & $\mathrm{m}^{1}$ & 121,00 & $\mathrm{Rp}$ & $348.000,00$ & $\mathrm{Rp}$ & $42.108 .000,00$ \\
\hline 14 & Pan drain & - & bh & 6,00 & $\mathrm{Rp}$ & $1.177 .000,00$ & $\mathrm{Rp}$ & $7.062 .000,00$ \\
\hline 15 & Plenum supply dan return & - & $\mathrm{bh}$ & 12,00 & $\mathrm{Rp}$ & $\begin{array}{l}3.901 .000,00 \\
\end{array}$ & $\mathrm{Rp}$ & $46.812 .000,00$ \\
\hline 16 & Supply Air Diffuser 250 × 250 & - & bh & 32,00 & $\mathrm{Rp}$ & $422.000,00$ & $\mathrm{Rp}$ & $13.504 .000,00$ \\
\hline 17 & Return Air Grille 200 x 600 & - & bh & 18,00 & $\mathrm{Rp}$ & $568.000,00$ & $\mathrm{Rp}$ & $10.224 .000,00$ \\
\hline 18 & Pengisian freon R410 & - & lot & 1,00 & $\mathrm{Rp}$ & $11.476 .000,00$ & $\mathrm{Rp}$ & $11.476 .000,00$ \\
\hline \multicolumn{7}{|r|}{ SUB TOTAL II - D } & $\mathbf{R p}$ & $676.791 .000,00$ \\
\hline \multicolumn{7}{|c|}{ SUB TOTAL II $(A+B+C+D)$} & Rp & $2.819 .006 .000,00$ \\
\hline & & & & & & & & \\
\hline III & PEKERJAAN INSTALASI LISTRIK \& SANITASI & & & & & & & \\
\hline $\mathbf{A}$ & LISTRIK - LANTAI 1 & & & & & & & \\
\hline 1 & Pas. Stop Kontak Panasonic & - & $\mathrm{Bh}$ & 50,00 & $\mathrm{Rp}$ & $34.337,16$ & $\mathrm{Rp}$ & $1.716 .858,00$ \\
\hline 2 & Pas. Saklar Ganda Panasonic & - & $\mathrm{Bh}$ & 27,00 & $\mathrm{Rp}$ & $28.022,28$ & $\mathrm{Rp}$ & $756.601,64$ \\
\hline 3 & Pas. Saklar Tunggal Panasonic & - & $\mathrm{Bh}$ & 5,00 & $\mathrm{Rp}$ & $16.885,00$ & $\mathrm{Rp}$ & $84.425,00$ \\
\hline 4 & Pas. Lampu Down Light LED 9 Watt & - & $\mathrm{Bh}$ & 177,00 & $\mathrm{Rp}$ & $107.315,00$ & $\mathrm{Rp}$ & $18.994 .755,00$ \\
\hline 5 & Pas. Lampu Down Light LED $2 \times 9$ Watt & - & $\mathrm{Bh}$ & 14,00 & $\mathrm{Rp}$ & $214.630,00$ & $\mathrm{Rp}$ & $3.004 .820,00$ \\
\hline 6 & Pas. Lampu RM TL T5 1x28Watt & - & $\mathrm{Bh}$ & 14,00 & $\mathrm{Rp}$ & $889.000,00$ & $\mathrm{Rp}$ & $12.446 .000,00$ \\
\hline 7 & Pas. Lampu RM TL T5 2x28Watt & - & $\mathrm{Bh}$ & 15,00 & $\mathrm{Rp}$ & $1.106 .000,00$ & $\mathrm{Rp}$ & $16.590 .000,00$ \\
\hline 8 & Pas. Lampu Gantung & - & $\mathrm{Bh}$ & 1,00 & $\mathrm{Rp}$ & $1.068 .000,00$ & $\mathrm{Rp}$ & $1.068 .000,00$ \\
\hline 9 & Pas. Instalasi titik lampu & - & Ttk & 223,00 & $\mathrm{Rp}$ & $347.000,00$ & $\mathrm{Rp}$ & $77.381 .000,00$ \\
\hline 10 & Pas. Instalasi titik Stop kontak & - & Ttk & 50,00 & Rp & $377.000,00$ & Rp & $18.850 .000,00$ \\
\hline 11 & Pas. Panel Penerangan \& Stopkontak Lt-1 & - & $\mathrm{Bh}$ & 1,00 & $\mathrm{Rp}$ & $17.639 .000,00$ & $\mathrm{Rp}$ & $17.639 .000,00$ \\
\hline 12 & Pas. Panel AC Lt-1 & - & $\mathrm{Bh}$ & 1,00 & $\mathrm{Rp}$ & $17.639 .000,00$ & $\mathrm{Rp}$ & $17.639 .000,00$ \\
\hline 13 & Pas. Panel LVMDP & - & $\mathrm{Bh}$ & 1,00 & $\mathrm{Rp}$ & $16.840 .000,00$ & $\mathrm{Rp}$ & $16.840 .000,00$ \\
\hline 14 & Pas. Panel Pompa Air Bersih & - & $\mathrm{Bh}$ & 1,00 & $\mathrm{Rp}$ & $7.621 .000,00$ & $\mathrm{Rp}$ & $7.621 .000,00$ \\
\hline 15 & Pas. Kabel power NYFGBY 4 x $120 \mathrm{~mm}^{2}$ LVMDP - PLN & - & $\mathrm{m}^{\prime}$ & 75,00 & $\mathrm{Rp}$ & $54.800,00$ & $\mathrm{Rp}$ & $4.110 .000,00$ \\
\hline 16 & 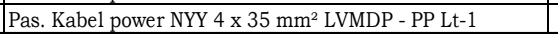 & - & $\mathrm{m}^{\prime}$ & 9,00 & $\mathrm{Rp}$ & $18.600,00$ & $\mathrm{Rp}$ & $167.400,00$ \\
\hline 17 & 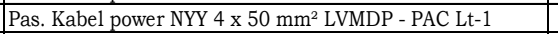 & - & $\mathrm{m}^{\prime}$ & 9,00 & $\mathrm{Rp}$ & $125.235,00$ & $\mathrm{Rp}$ & $1.127 .115,00$ \\
\hline 18 & Pas. Kabel power NYY 4 × $10 \mathrm{~mm}^{2}$ LVMDP - PAB & - & $\mathrm{m}^{\prime}$ & 45,00 & $\mathrm{Rp}$ & $52.200,00$ & $\mathrm{Rp}$ & $2.349 .000,00$ \\
\hline 19 & Pas. Kabel Tray 300 x $100 \mathrm{~mm}$ & - & $\mathrm{m}^{\prime}$ & 86,00 & $\mathrm{Rp}$ & $338.000,00$ & $\mathrm{Rp}$ & $29.068 .000,00$ \\
\hline \multirow[t]{2}{*}{20} & Pas. Arde & - & Ls & 1,00 & $\mathrm{Rp}$ & $2.854 .000,00$ & $\mathrm{Rp}$ & $2.854 .000,00$ \\
\hline & & - & & & & & & \\
\hline 21 & $\begin{array}{l}\text { Air Terminal type electrostatic ( Prevectron 3) radius } 100 \\
\text { meter }\end{array}$ & - & $\mathrm{bh}$ & 1,00 & $\mathrm{Rp}$ & $7.757 .000,00$ & $\mathrm{Rp}$ & $7.757 .000,00$ \\
\hline \multirow[t]{2}{*}{22} & $\begin{array}{l}\text { Grounding (Electroda \& plat tembaga, resistensi max } 2 \\
\text { ohm) }\end{array}$ & - & ls & 1,00 & $\mathrm{Rp}$ & $3.927 .000,00$ & $\mathrm{Rp}$ & $3.927 .000,00$ \\
\hline & Include box control & - & & & & & & \\
\hline 24 & Tesl Link & - & ls & 1,00 & $\mathrm{Rp}$ & $232.300,00$ & $\mathrm{Rp}$ & $232.300,00$ \\
\hline 25 & Construction Obstruction Lamp & - & bh & 1,00 & $\mathrm{Rp}$ & $3.385 .000,00$ & $\mathrm{Rp}$ & $3.385 .000,00$ \\
\hline 26 & NYY $1 \times 70 \mathrm{~mm} 2$ & - & $\mathrm{m}^{\prime}$ & 80,00 & $\mathrm{Rp}$ & $297.800,00$ & $\mathrm{Rp}$ & $23.824 .000,00$ \\
\hline 27 & Tiang penyangga & - & $\mathrm{bh}$ & 1,00 & $\mathrm{Rp}$ & $2.219 .000,00$ & $\mathrm{Rp}$ & $2.219 .000,00$ \\
\hline 28 & Support Material & - & ls & 1,00 & $\mathrm{Rp}$ & $1.668 .000,00$ & $\mathrm{Rp}$ & $1.668 .000,00$ \\
\hline 29 & Perijinan & - & ls & 1,00 & $\mathrm{Rp}$ & $4.423 .000,00$ & $\mathrm{Rp}$ & $4.423 .000,00$ \\
\hline \multicolumn{7}{|c|}{ SUB TOTAL III - A } & $\mathbf{R p}$ & $297.742 .274,64$ \\
\hline B & SANITASI - LANTAI 1 & & & & & & & \\
\hline 1 & Pas. Pipa Galvanis 3/4" & 7.a & $\mathrm{m}^{\prime}$ & 120,00 & $\mathrm{Rp}$ & $40.656,23$ & $\mathrm{Rp}$ & $4.878 .748,00$ \\
\hline 2 & Pas. Pipa Galvanis 1" & 7.b & $\mathrm{m}^{\prime}$ & 33,00 & $\mathrm{Rp}$ & \begin{tabular}{|l|l}
$44.531,23$ \\
\end{tabular} & $\mathrm{Rp}$ & $1.469 .530,70$ \\
\hline 3 & Pas. Pipa Galvanis $11 / 2^{\prime \prime}$ & 7.c & $\mathrm{m}^{\prime}$ & 42,00 & $\mathrm{Rp}$ & $71.021,43$ & $\mathrm{Rp}$ & $2.982 .900,20$ \\
\hline 4 & Pas. Gate Valve 1" & - & bh & 1,00 & $\mathrm{Rp}$ & $1.976,92$ & $\mathrm{Rp}$ & $1.976,92$ \\
\hline 5 & Pas. Gate Valve $11 / 2^{\prime \prime}$ & - & bh & 2,00 & $\mathrm{Rp}$ & $99.245,00$ & $\mathrm{Rp}$ & $198.490,00$ \\
\hline 6 & Pas. Pompa submersible 1 ltr/dtk H-50m berikut perlengk & - & bh & 1,00 & $\mathrm{Rp}$ & $99.245,00$ & $\mathrm{Rp}$ & $99.245,00$ \\
\hline 7 & Pas. Pipa PVC dia. 1 (Venting) & 7.d & $\mathrm{m}^{\prime}$ & 92,00 & $\mathrm{Rp}$ & $36.556,80$ & $\mathrm{Rp}$ & $3.363 .225,60$ \\
\hline 8 & Pas. Pipa PVC dia. 1 1/2" (Mandi/Cuci) & 7.e & $\mathrm{m}^{\prime}$ & 12,00 & $\mathrm{Rp}$ & $56.772,70$ & $\mathrm{Rp}$ & $681.272,40$ \\
\hline 9 & Pas. Pipa PVC dia. 3" (Mandi/Cuci) & $7 . f$ & $\mathrm{~m}^{\prime}$ & 12,00 & $\mathrm{Rp}$ & $118.792,90$ & $\mathrm{Rp}$ & $1.425 .514,80$ \\
\hline 10 & Pas. Pipa PVC dia. 4" (Mandi/Cuci) & $7 . \mathrm{g}$ & $\mathrm{m}^{\prime}$ & 84,00 & $\mathrm{Rp}$ & $160.642,90$ & $\mathrm{Rp}$ & $13.494 .003,60$ \\
\hline 11 & Pas. Pipa PVC dia. 4" (Air Kotor) & $7 . \mathrm{g}$ & $\mathrm{m}^{\prime}$ & 84,00 & $\mathrm{Rp}$ & $160.642,90$ & $\mathrm{Rp}$ & $13.494 .003,60$ \\
\hline 12 & Pas. Clean Out dia. 4" (Air Kotor) & - & bh & 2,00 & $\mathrm{Rp}$ & $423.000,00$ & $\mathrm{Rp}$ & $846.000,00$ \\
\hline 13 & Pas. Clean Out dia. 3" (Mandi/Cuci) & - & bh & 2,00 & $\mathrm{Rp}$ & $381.000,00$ & $\mathrm{Rp}$ & $762.000,00$ \\
\hline 14 & Pas. Septictank kap. $3 \mathrm{~m}^{3}$ & - & bh & 2,00 & $\mathrm{Rp}$ & $945.000,00$ & $\mathrm{Rp}$ & $1.890 .000,00$ \\
\hline 15 & Pek. Bak Kontrol & - & $\mathrm{Bh}$ & 2,00 & $\mathrm{Rp}$ & $758.000,00$ & $\mathrm{Rp}$ & $1.890 .000,00$ \\
\hline 16 & Pas.Urinoir & $7 . j$ & $\mathrm{Bh}$ & 3,00 & $\mathrm{Rp}$ & $1.348 .957,52$ & $\mathrm{Rp}$ & $4.046 .872,57$ \\
\hline 17 & Pas. Westafel & $7 . \mathrm{i}$ & $\mathrm{Bh}$ & 7,00 & $\mathrm{Rp}$ & $1.169 .525,76$ & $\mathrm{Rp}$ & $8.186 .680,35$ \\
\hline 18 & Pas. Toilet duduk & 7.h & $\mathrm{Bh}$ & 8,00 & $\mathrm{Rp}$ & $2.874 .095,96$ & $\mathrm{Rp}$ & $22.992 .767,68$ \\
\hline & & & & & & JB TOTAL III - B & $\mathbf{R p}$ & $82.703 .231,43$ \\
\hline
\end{tabular}


JURNAL KACAPURI

JURNAL KEILMUAN TEKNIK SIPIL

Volume 4 Nomor 2 Edisi Desember 2021

\begin{tabular}{|c|c|c|c|c|c|c|c|c|}
\hline \multirow[t]{2}{*}{$\mathrm{C}$} & \multicolumn{8}{|l|}{ PEKERJAAN DATA } \\
\hline & PERALATAN UTAMA & & & & & & & \\
\hline 1 & Server & - & $\mathrm{Bh}$ & 1,00 & Rp & $28.304 .000,00$ & $\mathrm{Rp}$ & $28.304 .000,00$ \\
\hline 2 & Personal Computer & - & $\mathrm{Bh}$ & 1,00 & $\mathrm{Rp}$ & $10.684 .000,00$ & $\mathrm{Rp}$ & $10.684 .000,00$ \\
\hline 3 & Printer & - & $\mathrm{Bh}$ & 1,00 & $R p$ & $5.186 .000,00$ & $\mathrm{Rp}$ & $5.186 .000,00$ \\
\hline 4 & Router & - & $\mathrm{Bh}$ & 1,00 & $\mathrm{Rp}$ & $3.821 .000,00$ & $\mathrm{Rp}$ & $3.821 .000,00$ \\
\hline 5 & Main Switch Hub 48 port & - & $\mathrm{Bh}$ & 1,00 & $\mathrm{Rp}$ & $15.978 .000,00$ & $\mathrm{Rp}$ & $15.978 .000,00$ \\
\hline 6 & Switch Hub 24 port & - & $\mathrm{Bh}$ & 2,00 & $R p$ & $7.677 .000,00$ & $\mathrm{Rp}$ & $15.354 .000,00$ \\
\hline 7 & Arrester & - & $\mathrm{Bh}$ & 1,00 & $\mathrm{Rp}$ & $1.774 .000,00$ & $\mathrm{Rp}$ & $1.774 .000,00$ \\
\hline 8 & UPS 2 KVA & - & $\mathrm{Bh}$ & 1,00 & Rp & $13.661 .000,00$ & $\mathrm{Rp}$ & $13.661 .000,00$ \\
\hline 9 & Wire Management & - & Ls & 1,00 & $R p$ & $6.824 .000,00$ & $\mathrm{Rp}$ & $6.824 .000,00$ \\
\hline 10 & Standing Rack & - & Unit & 1,00 & $R p$ & $11.829 .000,00$ & $\mathrm{Rp}$ & $11.829 .000,00$ \\
\hline 11 & Setting Peralatan Utama + Testing Commissioning & - & Lot & 1,00 & $\mathrm{Rp}$ & $13.328 .000,00$ & $\mathrm{Rp}$ & $13.328 .000,00$ \\
\hline & & & & & & & & \\
\hline & LANTAI - 1 & & & & & & & \\
\hline 1 & Wall Mount Rack & - & unit & 1,00 & Rp & $10.646 .000,00$ & $\mathrm{Rp}$ & $10.646 .000,00$ \\
\hline 2 & Switch Hub 24 Port & - & unit & 1,00 & $\mathrm{Rp}$ & $6.449 .000,00$ & $\mathrm{Rp}$ & $6.449 .000,00$ \\
\hline 3 & Patch Panel 24 Port & - & unit & 1,00 & $\mathrm{Rp}$ & $5.596 .000,00$ & $\mathrm{Rp}$ & $5.596 .000,00$ \\
\hline 4 & Data Outlet & - & bh & 13,00 & Rp & $282.000,00$ & Rp & $3.666 .000,00$ \\
\hline 5 & Instalasi Kabel LAN & - & ttk & 13,00 & $\mathrm{Rp}$ & $633.000,00$ & $\mathrm{Rp}$ & $8.229 .000,00$ \\
\hline & & & & & & & & \\
\hline & LANTAI - 2 & & & & & & & \\
\hline 1 & Wall Mount Rack & - & unit & 1,00 & $\mathrm{Rp}$ & $10.646 .000,00$ & $\mathrm{Rp}$ & $10.646 .000,00$ \\
\hline 2 & Switch Hub 24 Port & - & unit & 1,00 & $R p$ & $6.449 .000,00$ & $\mathrm{Rp}$ & $6.449 .000,00$ \\
\hline 3 & Patch Panel 24 Port & - & unit & 1,00 & $\mathrm{Rp}$ & $5.596 .000,00$ & $\mathrm{Rp}$ & $5.596 .000,00$ \\
\hline 4 & Data Outlet & - & bh & 13,00 & $R p$ & $282.000,00$ & $\mathrm{Rp}$ & $3.666 .000,00$ \\
\hline 5 & Instalasi Kabel LAN & - & ttk & 13,00 & $\mathrm{Rp}$ & $633.000,00$ & $\mathrm{Rp}$ & $8.229 .000,00$ \\
\hline & & & & & & JB TOTAL IV - C & $\mathbf{R p}$ & $195.915 .000,00$ \\
\hline & & & & & & & & \\
\hline D & PEKERJAAN MATV & & & & & & & \\
\hline & Peralatan Utama & & & & & & & \\
\hline 1 & Antena UHV & - & unit & 1,00 & $\mathrm{Rp}$ & $2.723 .000,00$ & $\mathrm{Rp}$ & $2.723 .000,00$ \\
\hline 2 & Antena VHF & - & unit & 1,00 & Rp & $1.956 .000,00$ & $\mathrm{Rp}$ & $1.956 .000,00$ \\
\hline 3 & Divider & - & unit & 1,00 & $\mathrm{Rp}$ & $971.000,00$ & $\mathrm{Rp}$ & $971.000,00$ \\
\hline 4 & Modulator & - & unit & 1,00 & $R p$ & $4.811 .000,00$ & $\mathrm{Rp}$ & $4.811 .000,00$ \\
\hline 5 & Main Spliter & - & unit & 1,00 & $\mathrm{Rp}$ & $971.000,00$ & $\mathrm{Rp}$ & $971.000,00$ \\
\hline 6 & Main Boster & - & unit & 1,00 & $\mathrm{Rp}$ & $7.882 .000,00$ & $\mathrm{Rp}$ & $7.882 .000,00$ \\
\hline 7 & Head end CATV & - & unit & 1,00 & $R p$ & $8.176 .000,00$ & $\mathrm{Rp}$ & $8.176 .000,00$ \\
\hline 8 & Spliter 2 way & - & unit & 1,00 & $\mathrm{Rp}$ & $1.253 .000,00$ & $\mathrm{Rp}$ & $1.253 .000,00$ \\
\hline 9 & Spliter 4 way & - & unit & 2,00 & $\mathrm{Rp}$ & $1.355 .000,00$ & $\mathrm{Rp}$ & $2.710 .000,00$ \\
\hline 10 & Active combiner & - & unit & 1,00 & $\mathrm{Rp}$ & $5.578 .000,00$ & $\mathrm{Rp}$ & $5.578 .000,00$ \\
\hline & INSTALASI MATV & & & & & & & \\
\hline & LANTAI - 1 & & & & & & & \\
\hline 1 & Stop Kontak power & - & bh & 1,00 & $\mathrm{Rp}$ & $50.000,00$ & $\mathrm{Rp}$ & $50.000,00$ \\
\hline 2 & Boster $48 \mathrm{db}$ & - & bh & 1,00 & $\mathrm{Rp}$ & $3.494 .000,00$ & $\mathrm{Rp}$ & $3.494 .000,00$ \\
\hline 3 & Outlet TV & - & bh & 1,00 & $\mathrm{Rp}$ & $109.000,00$ & $\mathrm{Rp}$ & $109.000,00$ \\
\hline 4 & Tap off 2 way & - & bh & 1,00 & $\mathrm{Rp}$ & $597.000,00$ & $\mathrm{Rp}$ & $597.000,00$ \\
\hline 5 & Tap off 4 way & - & bh & 1,00 & $\mathrm{Rp}$ & $832.000,00$ & $\mathrm{Rp}$ & $832.000,00$ \\
\hline 6 & Instalasi (kabel RG 6+counduit ega) & - & ttk & 1,00 & $\mathrm{Rp}$ & $706.000,00$ & $\mathrm{Rp}$ & $706.000,00$ \\
\hline & LANTAI - 2 & & & & $\mathrm{Rp}$ & - & & \\
\hline 1 & Stop Kontak power & - & bh & 1,00 & $\mathrm{Rp}$ & $50.000,00$ & $\mathrm{Rp}$ & $50.000,00$ \\
\hline 2 & Boster $48 \mathrm{db}$ & - & bh & 1,00 & $\mathrm{Rp}$ & $3.494 .000,00$ & $\mathrm{Rp}$ & $3.494 .000,00$ \\
\hline 3 & Outlet TV & - & bh & 1,00 & $\mathrm{Rp}$ & $109.000,00$ & $\mathrm{Rp}$ & $109.000,00$ \\
\hline 4 & Tap off 2 way & - & bh & 1,00 & $\mathrm{Rp}$ & $597.000,00$ & $\mathrm{Rp}$ & $597.000,00$ \\
\hline 5 & Tap off 4 way & - & bh & 1,00 & $\mathrm{Rp}$ & $832.000,00$ & $\mathrm{Rp}$ & $832.000,00$ \\
\hline 6 & Instalasi (kabel RG 6+counduit ega) & - & ttk & 1,00 & $\mathrm{Rp}$ & $706.000,00$ & $\mathrm{Rp}$ & $706.000,00$ \\
\hline & & & & & & B TOTAL IV - D & $\mathbf{R p}$ & $48.607 .000,00$ \\
\hline & & & & & & & & \\
\hline & & & & & & & & \\
\hline $\mathbf{E}$ & PEKERJAAN SOUND SISTEM & & & & & & & \\
\hline & Lantai - 1 & & & & & & & \\
\hline & RUANG AULA & & & & & & & \\
\hline 1 & Amplifier 240 watt & - & bh & 1,00 & $\mathrm{Rp}$ & $3.899 .000,00$ & $\mathrm{Rp}$ & $3.899 .000,00$ \\
\hline 2 & Mixer & - & bh & 1,00 & $\mathrm{Rp}$ & $10.526 .000,00$ & $\mathrm{Rp}$ & $10.526 .000,00$ \\
\hline 3 & Radio tuner, dvd player, deck \& mic public address & - & bh & 1,00 & Rp & $13.332 .000,00$ & $\mathrm{Rp}$ & $13.332 .000,00$ \\
\hline 4 & Microphone desk & - & bh & 1,00 & Rp & $1.287 .000,00$ & $\mathrm{Rp}$ & $1.287 .000,00$ \\
\hline 5 & Speaker Switch Selection 10 zone & - & bh & 1,00 & $\mathrm{Rp}$ & $3.767 .000,00$ & $\mathrm{Rp}$ & $3.767 .000,00$ \\
\hline 6 & MDF - SS & - & bh & 1,00 & $\mathrm{Rp}$ & $791.000,00$ & $\mathrm{Rp}$ & $791.000,00$ \\
\hline 7 & Rack Sound sistem $19 \mathrm{RU}$ & - & bh & 1,00 & $\mathrm{Rp}$ & $9.180 .000,00$ & $\mathrm{Rp}$ & $9.180 .000,00$ \\
\hline 8 & Kolom Speaker & - & bh & 6,00 & Rp & $3.662 .000,00$ & $\mathrm{Rp}$ & $21.972 .000,00$ \\
\hline 9 & Instalasi sound sistem & - & ttk & 6,00 & Rp & $685.000,00$ & $\mathrm{Rp}$ & $4.110 .000,00$ \\
\hline 10 & Wiring sistem peralatan utama & - & ls & 1,00 & $\mathrm{Rp}$ & $1.569 .000,00$ & $\mathrm{Rp}$ & $1.569 .000,00$ \\
\hline & RUANG UMUM & & & & & & & \\
\hline 1 & Amplifier 240 watt & - & bh & 1,00 & Rp & $3.899 .000,00$ & $\mathrm{Rp}$ & $3.899 .000,00$ \\
\hline 2 & Mixer & - & bh & 1,00 & $\mathrm{Rp}$ & $10.526 .000,00$ & $\mathrm{Rp}$ & $10.526 .000,00$ \\
\hline 3 & Radio tuner, dvd player, deck \& mic public address & - & bh & 1,00 & $\mathrm{Rp}$ & $13.332 .000,00$ & $\mathrm{Rp}$ & $13.332 .000,00$ \\
\hline 4 & Microphone desk & - & bh & 1,00 & $\mathrm{Rp}$ & $1.287 .000,00$ & $\mathrm{Rp}$ & $1.287 .000,00$ \\
\hline 5 & Speaker Switch Selection 10 zone & - & bh & 1,00 & $\mathrm{Rp}$ & $3.767 .000,00$ & $\mathrm{Rp}$ & $3.767 .000,00$ \\
\hline 6 & MDF - SS & - & bh & 1,00 & $\mathrm{Rp}$ & $784.000,00$ & $\mathrm{Rp}$ & $784.000,00$ \\
\hline 7 & Rack Sound sistem $19 \mathrm{RU}$ & - & bh & 1,00 & $\mathrm{Rp}$ & $9.180 .000,00$ & $\mathrm{Rp}$ & $9.180 .000,00$ \\
\hline 8 & TB - SS & - & bh & 1,00 & $\mathrm{Rp}$ & $591.000,00$ & $\mathrm{Rp}$ & $591.000,00$ \\
\hline 9 & Celling Speaker, 3 watt & - & bh & 30,00 & $\mathrm{Rp}$ & $205.000,00$ & $\mathrm{Rp}$ & $6.150 .000,00$ \\
\hline 10 & Volume kontrol & - & bh & 16,00 & $\mathrm{Rp}$ & $369.000,00$ & $\mathrm{Rp}$ & $5.904 .000,00$ \\
\hline 11 & Instalasi sound sistem & - & $\mathrm{ttk}$ & 30,00 & $\mathrm{Rp}$ & $685.000,00$ & $\mathrm{Rp}$ & $20.550 .000,00$ \\
\hline 12 & Wiring sistem peralatan utama & - & Is & 1,00 & Rp & $1.569 .000,00$ & $\mathrm{Rp}$ & $1.569 .000,00$ \\
\hline
\end{tabular}

Sumber: Hasil Analisis 
JURNAL KACAPURI

JURNAL KEILMUAN TEKNIK SIPIL

Volume 4 Nomor 2 Edisi Desember 2021

\begin{tabular}{|c|c|c|c|}
\hline \multicolumn{2}{|r|}{ URAIAN PEKERJAAN } & \multicolumn{2}{|r|}{ JUMLAH } \\
\hline \multirow[t]{3}{*}{ A } & PEKERJAAN STRUKTUR & \multirow[b]{2}{*}{$\mathrm{Rp}$} & \multirow[b]{2}{*}{$3.409 .771 .520,79$} \\
\hline & I $\quad$ PEK. STRUKTUR RANGKA ATAP & & \\
\hline & II $\quad$ PEK. STRUKTUR BETON & $\mathrm{Rp}$ & $14.496 .894,62$ \\
\hline \multicolumn{2}{|r|}{ JUMLAH PEKERJAAN STRUKTUR } & $\mathbf{R p}$ & 3.424.268.415,41 \\
\hline \multirow[t]{9}{*}{ B } & PEKERJAAN ARSITEKTUR & & \\
\hline & LANTAI 1 & & \\
\hline & I $\quad$ PEKERJAAN PERSIAPAN & $\mathrm{Rp}$ & $4.500 .000,00$ \\
\hline & II $\quad$ PEKERJAAN PASANGAN DINDING + PLESTERAN + ACIAN & $\mathrm{Rp}$ & $1.109 .109 .044,12$ \\
\hline & III $\quad$ PEKERJAAN LANTAI \& DINDING KERAMIK & $\mathrm{Rp}$ & $518.459 .816,82$ \\
\hline & $\begin{array}{ll}\mathrm{IV} & \text { PEKERJAAN PINTU DAN JENDELA } \\
\end{array}$ & $\mathrm{Rp}$ & $95.700 .000,00$ \\
\hline & $\begin{array}{ll}\mathrm{V} & \text { PEKERJAAN PLAFOND } \\
\end{array}$ & $\mathrm{Rp}$ & $324.056 .757,40$ \\
\hline & VI $\quad$ PEKERJAAN PENGECATAN & $\mathrm{Rp}$ & $391.242 .602,34$ \\
\hline & $\begin{array}{ll}\text { VII } & \text { PEKERJAAN SECONDARY SKIN, ACCESSORY } \\
\end{array}$ & $\mathrm{Rp}$ & $16.300 .000,00$ \\
\hline \multicolumn{2}{|r|}{$\begin{array}{l}\text { JUM LAH PEKERJAAN ARSITEKTUR LANTAI } 1 \\
\end{array}$} & Rp & $2.459 .368 .220,68$ \\
\hline & LANTAI 2 & & \\
\hline & $\begin{array}{ll}\mathrm{I} & \text { PEKERJAAN PASANGAN DINDING } \\
\end{array}$ & $\mathrm{Rp}$ & $1.222 .403 .490,55$ \\
\hline & II $\quad$ PEKERJAAN LANTAI \& DINDING KERAMIK & $\mathrm{Rp}$ & $471.731 .889,84$ \\
\hline & III $\quad$ PEKERJAAN PINTU DAN JENDELA & $\mathrm{Rp}$ & $90.700 .000,00$ \\
\hline & IV $\quad$ PEKERJAAN PLAFOND & $\mathrm{Rp}$ & $378.196 .005,41$ \\
\hline & $\begin{array}{ll}\mathrm{V} & \text { PEKERJAAN PENGECATAN } \\
\end{array}$ & $\mathrm{Rp}$ & $420.017 .650,32$ \\
\hline & $\begin{array}{ll}\text { VI } & \text { PEKERJAAN PENUTUP ATAP } \\
\end{array}$ & $\mathrm{Rp}$ & $3.709 .846 .649,37$ \\
\hline \multicolumn{2}{|r|}{$\begin{array}{r}\text { JUMLAH PEKERJAAN ARSITEKTUR LANTAI } 2 \\
\end{array}$} & Rp & $6.292 .895 .685,48$ \\
\hline \multicolumn{2}{|r|}{ JUMLAH PEKERJAAN ARSITEKTUR } & Rp & $8.752 .263 .906,15$ \\
\hline \multirow[t]{3}{*}{$\mathbf{C}$} & PEKERJAAN INTERIOR \& ACP & & \\
\hline & I $\quad$ PEKERJAAN ACP & $\mathrm{Rp}$ & $120.250 .000,00$ \\
\hline & II $\quad$ PEKERJAAN INTERIOR & $\mathrm{Rp}$ & $64.272 .000,00$ \\
\hline \multicolumn{2}{|r|}{ JUMLAH PEKERJAAN INTERIOR \& ACP } & Rp & $184.522 .000,00$ \\
\hline \multirow[t]{10}{*}{ D } & PEKERJAAN MEKANIKAL ELEKTRIKAL PLUM BING \& IT & & \\
\hline & I $\quad$ PEKERJAAN PENYAMBUNGAN DAYA LISTRIK & $\mathrm{Rp}$ & $95.630 .000,00$ \\
\hline & II $\quad$ PEKERJAAN AC & $\mathrm{Rp}$ & $2.819 .006 .000,00$ \\
\hline & III $\quad$ PEKERJAAN LISTRIK \& PLUMBING & $\mathrm{Rp}$ & $703.890 .799,05$ \\
\hline & IV $\quad$ PEKERJAAN IT & $\mathrm{Rp}$ & $1.094 .241 .000,00$ \\
\hline & JUMLAH PEKERJAAN MEP DAN IT & $R p$ & $4.712 .767 .799,05$ \\
\hline & JUMLAH TOTAL & $\mathbf{R p}$ & $17.073 .822 .120,61$ \\
\hline & (OVERHEAD + PROFIT 15\%) & Rp & $2.561 .073 .318,09$ \\
\hline & JUMLAH TOTAL + (OVERHEAD + PROFIT 15\%) & $\mathrm{Rp}$ & $19.634 .895 .438,70$ \\
\hline & DIBULATKAN & Rp & $19.634 .000 .000,00$ \\
\hline
\end{tabular}

Sumber: Hasil Analisis

Perbandingan Hasil Perhitungan Pekerjaan Metode SNI 2010 dan Metode AHSP Bidang Cipta Karya Peraturan Menteri PUPR Nomor 28 Tahun 2016

Tabel 11. Perbandingan Total Rencana Anggaran Biaya

\begin{tabular}{|c|c|c|c|c|c|c|c|}
\hline \multirow{2}{*}{ NO } & \multirow{2}{*}{ URAIAN KEGIATAN } & \multirow{2}{*}{\multicolumn{2}{|c|}{ ANALISA SNI 2010}} & \multirow{2}{*}{\multicolumn{2}{|c|}{ AHSP PUPR 2016}} & Kenaikan & Penurunan \\
\hline & & & & & & $(\%)$ & $(\%)$ \\
\hline A & PEKERJAAN STRUKTUR & $\mathrm{Rp}$ & $2.991 .561 .644,81$ & $\mathrm{Rp}$ & $3.424 .168 .484,53$ & $12,63 \%$ & 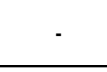 \\
\hline B & PEKERJAAN ARSITEKTUR & Rp & $8.748 .125 .320,23$ & Rp & $8.752 .263 .906,15$ & $0,05 \%$ & - \\
\hline C & PEKERJAAN INTERIOR \& ACH & Rp & $184.522,000,00$ & $\mathrm{Rp}$ & $184.522,000,00$ & $0,00 \%$ & - \\
\hline$D$ & PEKERJAANMEP \& IT & Rp & $4.712 .118 .084,25$ & $\mathrm{Rp}$ & $4.712 .767 .799,05$ & $0,01 \%$ & - \\
\hline
\end{tabular}

Sumber: Hasil Analisis 
JURNAL KACAPURI

JURNAL KEILMUAN TEKNIK SIPIL

Volume 4 Nomor 2 Edisi Desember 2021

Tabel 12. Deviasi

\begin{tabular}{|l|l|l|}
\hline \multirow{2}{*}{ Total } & ANALISIS SNI 2010 & AHSP PUPR 2016 \\
\cline { 2 - 3 } & \multicolumn{1}{|c|}{ Rp 19.131.776.000,00 } & Rp 19.634.780.000,00 \\
\hline Selisih & Rp $\mathbf{5 0 3 . 0 0 4 . 0 0 0 , 0 0}$ & \\
\hline Deviasi & $\mathbf{2 , 5 6 \%}$ & \\
\hline
\end{tabular}

Sumber: Hasil Analisis

\section{PENUTUP}

\section{Kesimpulan}

Hasil penelitian Perbandingan Rencana Anggaran Biaya pada Pekerjaan Pembangunan Gedung Kantor Pengadilan Tinggi Agama Banjarmasin Tahap II adalah sebagai berikut:Hasil perhitungan Rencana Anggaran Biaya menggunakan metode SNI 2010 adalah sebesar Rp 19.131.776.000,00; Hasil perhitungan Rencana Anggaran Biaya menggunakan metode AHSP Bidang Cipta Karya Peraturan Menteri PUPR Nomor 28 Tahun 2016 adalah sebesar Rp 19.634.780.000,00; Selisih total Rencana Anggaran Biaya adalah sebesar Rp 503.004.000,00; dengan persentase perbandingan sebesar $2,56 \%$. Penyebab adanya perbedaan pada total Rencana Anggaran Biaya metode SNI 2010 dan metode Analisa Harga Satuan Pekerjaan (AHSP) Bidang Cipta Karya Peraturan Menteri PUPR Nomor 28 Tahun 2016, adalah sebagai berikut: Pada Pekerjaan Struktur mengalami kenaikan harga satuan pekerjaan yaitu sebesar Rp.432.606.839,72; hal ini disebabkan: Pekerjaan baja mengalami kenaikan harga upah dan bahan seperti: Tukang besi, Mandor, Baja profil IWF. Pekerjaan bekisting kolom mengalami kenaikan harga upah seperti: Pekerja, Mandor. Pekerjaan pembesian kolom mengalami kenaikan harga upah seperti: Mandor Pada Pekerjaan Arsitektur mengalami kenaikan harga satuan pekerjaan yaitu sebesar Rp. 4.138.585,92; hal ini disebabkan: Pekerjaan plesteran semen Pc mengalami kenaikan harga upah dan bahan seperti: Pekerja, Mandor, Pasir pasang. Pekerjaan plesteran kolom-balok semen Pc mengalami kenaikan harga upah dan bahan seperti: Pekerja, Mandor, Pasir pasang. Pekerjaan list plafond mengalami kenaikan harga upah dan penambahan bahan seperti: Pekerja, Kepala tukang, Tukang kayu, Mandor, Penambahan paku. Pekerjaan cat list plafond mengalami kenaikan harga bahan dikarenakan pada Metode Analisa Harga Satuan Pekerjaan (AHSP) Bidang Cipta Karya Peraturan Menteri PUPR Nomor 28 Tahun 2016 ada tiga bahan yang bertambah seperti: Kuas, Pengencer, Ampelas. Pada Pekerjaan ACP dan Interior tidak mengalami kenaikan atau penurunan dikarenakan tidak menggunakan analisis tetapi menggunakan harga borongan. Pada Pekerjaaan Sanitasi untuk metode SNI 2010 sebesar $\quad$ Rp. 4.712.118.084,25; sedangkan untuk metode Analisa Harga Satuan Pekerjaan (AHSP) Bidang Cipta Karya Peraturan Menteri PUPR Nomor 28 Tahun 2016 sebesar Rp.4.712.767.799,05; menunjukan bahwa pekerjaan ini mengalami kenaikan sebesar 0,01 \%, Hal ini disebabkan: Pekerjaan Pemasangan Pipa Galvanis 3/4" mengalami kenaikan bahan seperti: Pipa Galvanis 3/4" Pekerjaan Pemasangan Pipa PVC dia 1" mengalami kenaikan Upah seperti: Mandor Pekerjaan Pemasangan Pipa PVC dia 1 1/2" mengalami kenaikan Upah seperti: Pekerja, Tukang batu, Kepala tukang, Mandor Pada Pekerjaan Westafel mengalami kenaikan Upah dan bahan seperti: Mandor, Westafel. Dari perbandingan perhitungan biaya yang dilakukan, jumlah total biaya pada metode SNI 2010 lebih ekonomis dibandingkan dengan metode Analisis Harga Satuan Pekerjaan (AHSP) Bidang Cipta Karya Peraturan Menteri PUPR Nomor 28 Tahun 2016. 
JURNAL KACAPURI

JURNAL KEILMUAN TEKNIK SIPIL

Volume 4 Nomor 2 Edisi Desember 2021

\section{DAFTAR PUSTAKA}

( - ) .2016. "Keputusan Walikota Banjarbaru tentang Penetapan Standar Harga Kota Banjarbaru”. Dinas Pekerjaan Umum dan Tata Ruang. Banjarbaru.

( - ).2017. “Keputusan Walikota Banjarbaru tentang Penetapan Standar Harga Kota Banjarbaru”. Dinas Pekerjaan Umum dan Tata Ruang. Banjarbaru.

A.Z. Zainal. 2005. ANALISIS BANGUNAN"MENGHITUNG ANGGARAN BIAYA BANGUNAN”. PT Gramedia Pustaka Utama. Jakarta.

Bachtiar Ibrahim. H. 1993, "Rencana dan Estimate Real of Cost”, Penerbit Bumi Aksara, Jakarta.

Badan Standar Konstruksi. 2008. "Perhitungan Harga Satuan Pekerjaan Konstruksi Bangunan Gedung dan Perumahan”. Badan Standarisasi Nasional. Jakarta.

Badan Standar Konstruksi. 2010. "Perhitungan Harga Satuan Pekerjaan Konstruksi Bangunan Gedung dan Perumahan”. Badan Standarisasi Nasional. Jakarta.

Kementerian Pekerjaan Umum dan Perumahan Rakyat. 2013. "Analisis Harga Satuan Pekerjaan Bidang Pekerjaan Umum”. Kementerian Pekerjaan Umum dan Perumahan Rakyat. Jakarta.

Kementerian Pekerjaan Umum dan Perumahan Rakyat. 2016. “Analisis Harga Satuan Pekerjaan Bidang Pekerjaan Umum”. Kementerian Pekerjaan Umum dan Perumahan Rakyat. Jakarta.

Lenggogeni, M.T. \& Irika Widiasanti, M.T., Ir. 2013. “Manajemen Konstruksi”. PT REMAJA ROSDAKARYA. Bandung.

Mukomoko J. A. Ir. 1987. “Dasar Penyusunan Anggaran Biaya Bangunan”. Graha Media Pratama. Jakarta.

Soedradjat Sastraadmadja. A. Ir. 1984, analisa (cara modern) “Anggaran Biaya Pelaksanaan”, Penerbit NOVA, Bandung. 